\title{
Phase transformations of microcrystalline cellulose under ball- milling and hydrothermal treatment
}

\author{
Sai Kishore Pyapalli \\ West Virginia University
}

Follow this and additional works at: https://researchrepository.wvu.edu/etd

\section{Recommended Citation}

Pyapalli, Sai Kishore, "Phase transformations of microcrystalline cellulose under ball-milling and hydrothermal treatment" (2013). Graduate Theses, Dissertations, and Problem Reports. 4991. https://researchrepository.wvu.edu/etd/4991

This Thesis is protected by copyright and/or related rights. It has been brought to you by the The Research Repository @ WVU with permission from the rights-holder(s). You are free to use this Thesis in any way that is permitted by the copyright and related rights legislation that applies to your use. For other uses you must obtain permission from the rights-holder(s) directly, unless additional rights are indicated by a Creative Commons license in the record and/ or on the work itself. This Thesis has been accepted for inclusion in WVU Graduate Theses, Dissertations, and Problem Reports collection by an authorized administrator of The Research Repository @ WVU. For more information, please contact researchrepository@mail.wvu.edu. 


\title{
PHASE TRANSFORMATIONS OF MICROCRYSTALLINE CELLULOSE UNDER BALL-MILLING AND HYDROTHERMAL TREATMENT
}

\author{
Sai KishorePyapalli
}

Thesis submitted to the College of Engineering and Mineral Resources at West Virginia University in partial fulfillment of the requirements for the degree of

Master of Science

in

Electrical Engineering

\author{
Muhammad A. Choudhry, Ph.D., Chair \\ Mohindar S. Seehra, Ph.D., Co-Chair \\ Yuxin Liu, Ph.D.
}

Lane Department of Computer Science and Electrical Engineering

\author{
Morgantown, West Virginia \\ 2013
}

Keywords: Cellulose, Hydrothermal Treatment, Ball-Milling 


\section{ABSTRACT \\ PHASE TRANSFORMATIONS OF MICROCRYSTALLINE CELLULOSE UNDER BALL-MILLING AND HYDROTHERMAL TREATMENT}

\section{Sai KishorePyapalli}

In this thesis, experimental results and their analysis are presented on the phase transformations of microcrystalline cellulose (MCC) under two different treatments. First, MCC was subjected to ball milling in air for different times $t_{\mathrm{BM}}=5,10,15,30,45,60$ and 120 minutes. Second, phase transformation of MCC under hydrothermal treatment (HTT) in distilled water using an autoclave was investigated by varying the pressure $\mathrm{P}$, temperature $\mathrm{T}$ for different time $\tau$. Both of the post treated samples were analyzed by X-Ray Diffraction (XRD), Fourier Transform Infrared (FTIR) Spectroscopy, surface area measurements, Scanning Electron Microscopy (SEM) and Thermo-gravimetric Analysis (TGA).

Experimental results on the structural changes observed in microcrystalline cellulose subjected to ball milling for upto 120 minutes are reported. Under ball milling, the Segal crystallinity $\mathrm{X}_{\mathrm{CR}}$ systematically decreases with increase in ball milling time $\mathrm{t}_{\mathrm{BM}}$ with the largest rate of decrease observed for the initial time $t_{B M}<30$ minutes. These results show transformation of crystalline cellulose to an amorphous cellulose phase. The results on the XRD above $t_{\mathrm{BM}}>30$ minutes are inconclusive to prove the presence of cellulose. Therefore evidence about the presence of cellulose above $t_{\mathrm{BM}}>30$ minutes is shown by analyzing the results from FTIR spectroscopy.

Under hydrothermal treatment in water using an autoclave in which pressure $\mathrm{P}$, temperature $\mathrm{T}$ and time of treatment $\tau$ were varied, the cellulose structure was observed to completely breakdown at the minimum conditions of $\mathrm{P} \approx 400 \mathrm{PSI}, \mathrm{T} \approx 230^{\circ} \mathrm{C}$ and $\tau \approx 30$ minutes. Analysis of the XRD patterns yields information only about conversion of crystalline to amorphous form and the presence of cellulose is still vague. Results of the FTIR spectroscopy shows that for higher $\mathrm{P}, \mathrm{T}$ and $\tau$, the cellulose structure has completely broken-down resulting in new chemical phases. This different chemical nature of the converted sample is also evident from its thermal behavior under TGA as compared to that of unconverted sample. 


\section{DEDICATION \\ To my Parents}

I dedicate this thesis to my parents; Mr. VIJAY KUMAR PYAPALLI and Mrs. JAYASRI PYAPALLI whose constant support and great patience in the pursuit of my education has made all this possible. Thanks are also extended to my sister PRATHYUSHA SAI PYAPALLI, grandparents, cousins and friends;Kamalesh, Sai Kumar and Shailajafor their constant encouragement and support. 


\section{ACKNOWLEDGEMENTS}

This thesis would not have been possible without the help, support and patience of my mentor, supervisor and research advisorDr. MohindarSeehra, not to mention his advice and unsurpassed knowledge in the various fields of Physics. I thank Dr. Seehra for believing in me in my initial career start at West Virginia University and providing me the opportunity to join his research team. In a span of two years under the mentoring of Dr. Seehra, I learned how to work patiently and present my work effectively with highest quality.

The good advice, support and friendship of my chair, Dr. Muhammad Choudhry, has been invaluable on both academic and personal level, for which I am extremely grateful. I thank my committee member Dr. Yuxin Liu for her constant support in my academics. I would like to acknowledge the financial, academic and technical support of the West Virginia University, Department of Electrical Engineering and Department of Physics that provided the necessary resources for this research. I also thank Mr. James Poston at NETL for the SEM data he provided.

This research was supported in part by a research grant from the U.S. Department of Energy (Contract \# DE-FC26-O5NT42456) with Prof. MohindarSeehra as the principal investigator. 


\section{TABLE OF CONTENTS}

ABSTRACT .ii

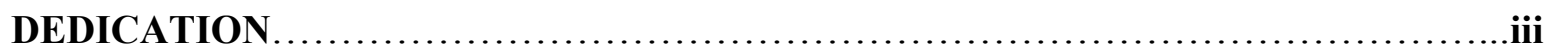

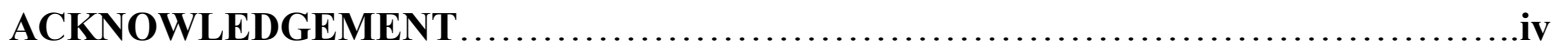

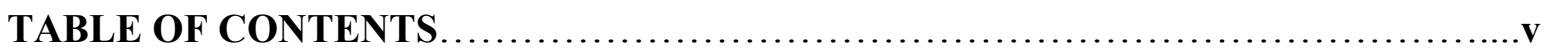

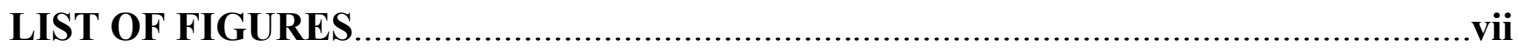

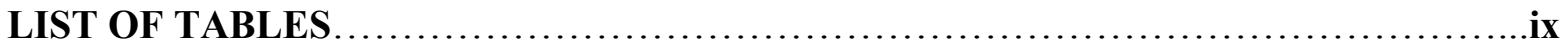

CHAPTER 1.INTRODUCTIONAND OBJECTIVES ..............................................

1.1 STRUCTURE OF CELLULOSE....................................

1.2 APPLICATIONS OF CELLULOSE................................

1.3 OBJECTIVES OF RESEARCH.................................

CHAPTER 2. EXPERIMENTAL PROCEDURES AND TECHNIQUES..................6

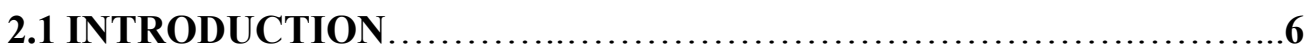

2.2 X-RAY DIFFRACTION ..........................................

2.2.1 Production of X-rays ........................................8

2.3 THERMOGRAVIMETRIC ANALYSIS..............................

2.4 FOURIER TRANSFORM INFRARED(FTIR) SPECTROSCOPY .....12

2.4.1 Working principle.....................................13

2.4.2 Sample preparation.......................................14

2.5 SCANNING ELECTRON MICROSCOPY(SEM) ...................15

2.6 SURFACE AREA MEASUREMEMNTS ............................16 
2.6.1 Procedure for measuring surface area........................17

2.7 HYDROTHERMAL TREATMENT (HTT) ........................18

2.7.1 Sample preparation...........................................18

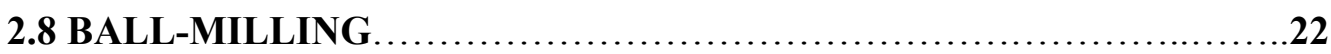

2.8.1 Procedure used for ball-milling............................22

CHAPTER 3.EXPERIMENTAL RESULTS ON BALL-MILLED CELLULOSE..........24

3.1 INTRODUCTION..............................................24

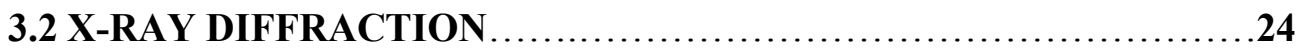

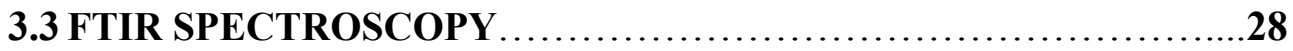

3.4 THERMOGRAVIMETRIC ANALYSIS.............................................

3.5 SCANNING ELECTRON MICROSCOPY ........................ 34

3.6 SURFACE AREA ....................................... 36

CHAPTER 4. EXPERIMENTAL RESULTS OF HTT CELLULOSE.................. 38

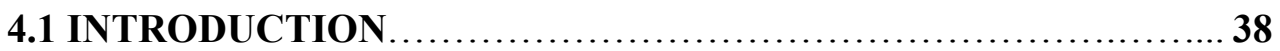

4.2 X-RAY DIFFRACTION $\ldots \ldots \ldots \ldots \ldots \ldots \ldots \ldots \ldots \ldots \ldots \ldots \ldots \ldots \ldots, 40$

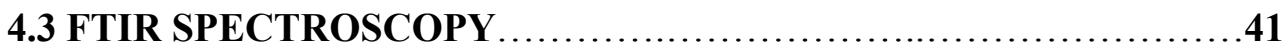

4.4 THERMO-GRAVIMETRIC ANALYSIS (TGA) .................42

4.5 SCANNING ELECTRON MICROSCOPY (SEM) ..................43

CHAPTER 5. CONCLUSIONS ............................................. 48

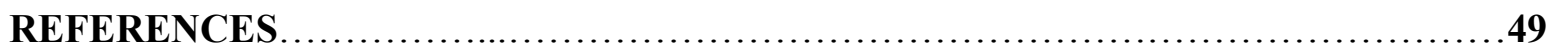

APPROVAL OF EMAMINING COMMITTEE..................................... 


\section{LIST OF FIGURES}

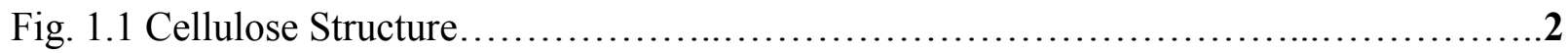

Fig. 1.2 Cellulose structure [Figure obtained from General Biomass Company]..................3

Fig. 2.1 Geometry for the explanation of Bragg's Law................................... 7

Fig.2.2 Focusing geometry of the Diffractometer........................................

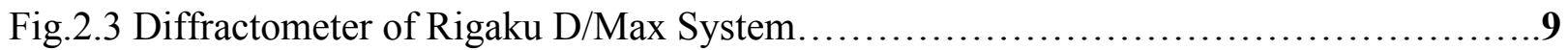

Fig2.4 Mortar and Pestle used in Lab...................................................

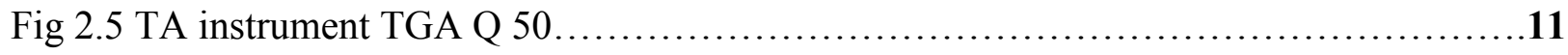

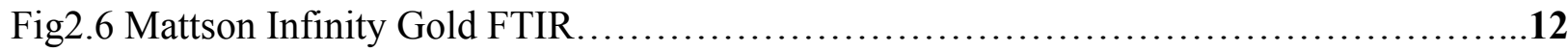

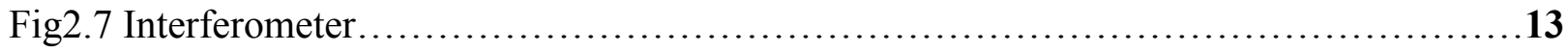

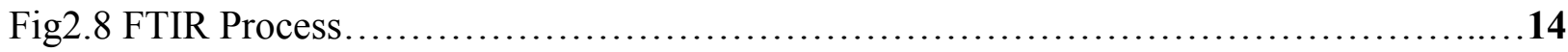

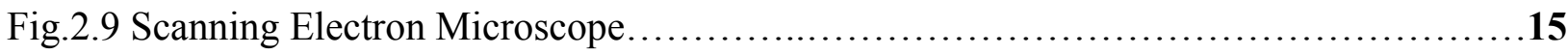

Fig 2.10 Autochem II 2920 used for surface area measurements..........................16

Fig2.11 Hydrothermal Setup ........................................................

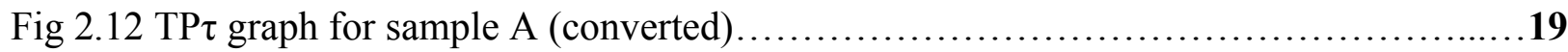

Fig $2.13 \mathrm{TP} \tau$ graph for partially converted sample F \&uncoverted sample B.................20

Fig 2.14 Centrifuge technique used in Lab..................................................

Fig 2.15 Shown is the comparison of samples before and after hydrothermal treatment.........21

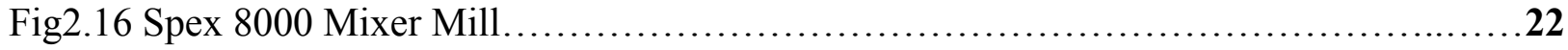

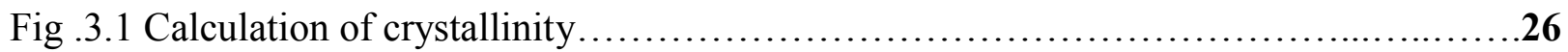

Fig. 3.2: XRD patterns of the microcrystalline cellulose samples ball-milled for the different

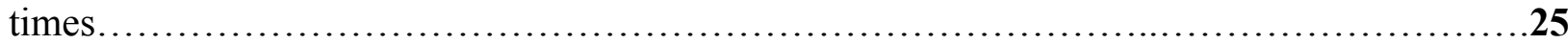

Fig. 3.3 Change in the Segal crystallinity parameter $\mathrm{X}_{\mathrm{CR}}(\%)$ and particle size with ball milling time. The line connecting the data points is for visual guide.

Fig. 3.4 IR spectra of MC samples ball-milled for different times are compared for the 500 to $4000 \mathrm{~cm}^{-1}$ range..

Fig. 3.5 IR spectra of MC samples ball-milled for different times are compared for the 500 to $2500 \mathrm{~cm}^{-1}$ range. 


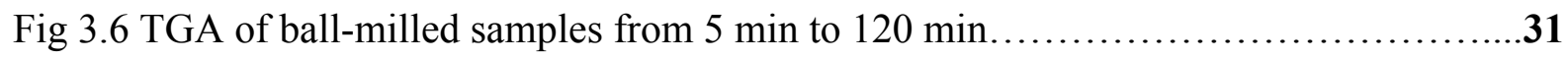

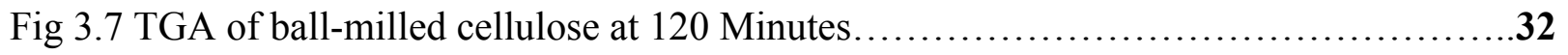

Fig. 3.8 TGA analysis of weight (W) change vs. temperature for several samples ball-milled for

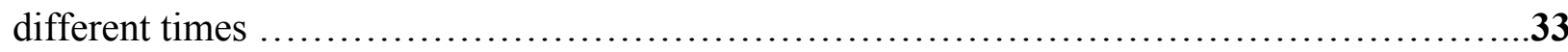

Fig. 3.9: SEM micrographs for MCC samples ball-milled for different times.................34

Fig. 3.10 Particle size distribution of 120 minute ball-milled sample.......................36

Fig. 3.11 BET surface area and total pore volume of the MCC samples ball-milled for different

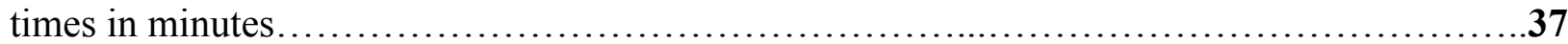

Figure 4.1: XRD patterns of the hydrothermally treated samples of MCC ...................39

Figure 4.2: FTIR Spectra for the $500 \mathrm{~cm}^{-1}$ to $2000 \mathrm{~cm}^{-1}$ range.........................40

Fig. 4.3 FTIR Spectra for the $500 \mathrm{~cm}^{-1}$ to $2000 \mathrm{~cm}^{-1}$ range.............................

Fig. 4.4 TGA plot of the three hydrothermally processed MCC samples of Table $4.1 \ldots \ldots . \ldots . . .43$

Fig. 4.5 SEM micrographs of the unconverted samples..............................44

Fig.4.6 SEM micrographs of partially converted samples showing formation of spherical

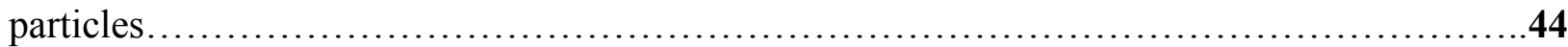

Fig. 4.7 SEM micrographs of converted samples showing nearly spherical particles...........45

Fig. 4.8 Size distribution of the spherical particles present in the converted sample.............46 


\section{LIST OF TABLES}

Table.3.1 Crystallinity of the ball-milled samples........................................27

Table 3.2 Assignments of the major IR bands (listed in $\mathrm{cm}^{-1}$ ) observed in the parent and post

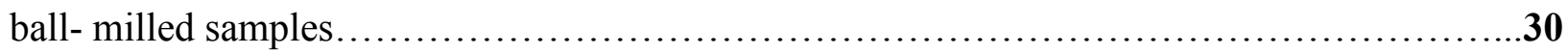

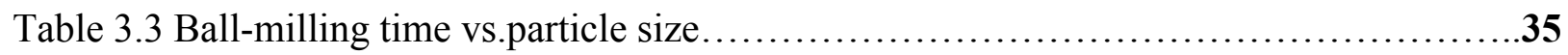

Table 4.1 Magnitudes of the T, P and $\tau$ parameters for the different samples along with $\%$ recovery and $\%$ crystallinity (where applicable) are listed..................................38

Table 4.2 Assignments of the major IR bands (listed in $\mathrm{cm}^{-1}$ ) observed in the parent and post-

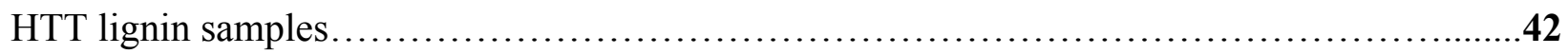

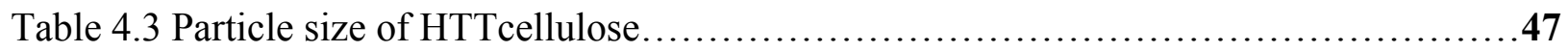




\section{INTRODUCTION AND OBJECTIVES}

Withthe continuedincrease in population and standard of living around the world, there is increasing need for energy supply, especially cleanly generated electricity. Electricity demand is increasing twice as fast as overall energy use and is likely to rise by about $75 \%$ by 2030 , according to the World Nuclear Association. Many power stations across the world burn fossil fuels such as coal,oil and gas to generate electricity. When the fossil fuels are burned they release carbon dioxide into the atmosphere which is believed to contribute to global warming. Using fossil fuels to generate energy also releases pollutants into the atmosphere such as sulphurdioxide. The average gasoline price in 2003 was $1.43 \$$ per gallon, in this year (2013) the average gasoline price is $3.95 \$$ per gallon. This high drift in gas prices within a decade is one of the major world problems as the supply of fossils fuels is believed to be decreasingfaster than anticipated. Hence consumers, industry and government are increasingly demanding products made from the renewable and sustainable resources.

The major clean energy generating component of non-food crops is cellulose, with lignin second. Cellulose is known to be a clean energy carrier obtained from the natural and renewable energy resources such as wood, hemp, cotton, linen and grass. Cellulose is the most abundant organic matter in biosphere. Cellulose is amenable for conversion to sugars which in turn can be biodegraded to alcohols which can be used in energy generation. Cellulose ethanol has been receiving increasing attention in order to reduce the effects of $\mathrm{CO}_{2}$ green house gas emissions resulting from the use of fossil fuels.

\subsection{Structure of cellulose}

Cellulose is a major component of biomass $(\sim 45 \%)$, the other components being hemi-cellulose $(\sim 30 \%)$, lignin $(\sim 20 \%)$, pectin $(\sim$ few $\%)$ and other minor phases (Browning 1965$)$. Two recent review papers have summarized the various properties of cellulose materials (Habibi et al 2010 and Moon et al 2011). 
D-glucose is a sugar with formula $\mathrm{C}_{6} \mathrm{H}_{12} \mathrm{O}_{6}$. It is soluble in water and is used by all life for energy. Cellulose is a crystalline polysaccharide made of linear chain with the formula $\left(\mathrm{C}_{6} \mathrm{H}_{10} \mathrm{O}_{5}\right)_{\mathrm{n}}$ see Fig 1.1. It has a flat ribbon like conformation with neighboring units corkscrewed $180^{\circ}$ with $\mathrm{OH}$ units in the ring plane. Cellulose is an important structural component of the primary cell wall of green plants, many forms of algae. Cellulose polymer consisting of a linear chain of several hundred to over ten thousand $\beta(1 \rightarrow 4)$ linked D-glucose units. The cellulose content of cotton fiber is $90 \%$, that of wood is $40-50 \%$ and that of dried hemp is approximately $45 \%$.

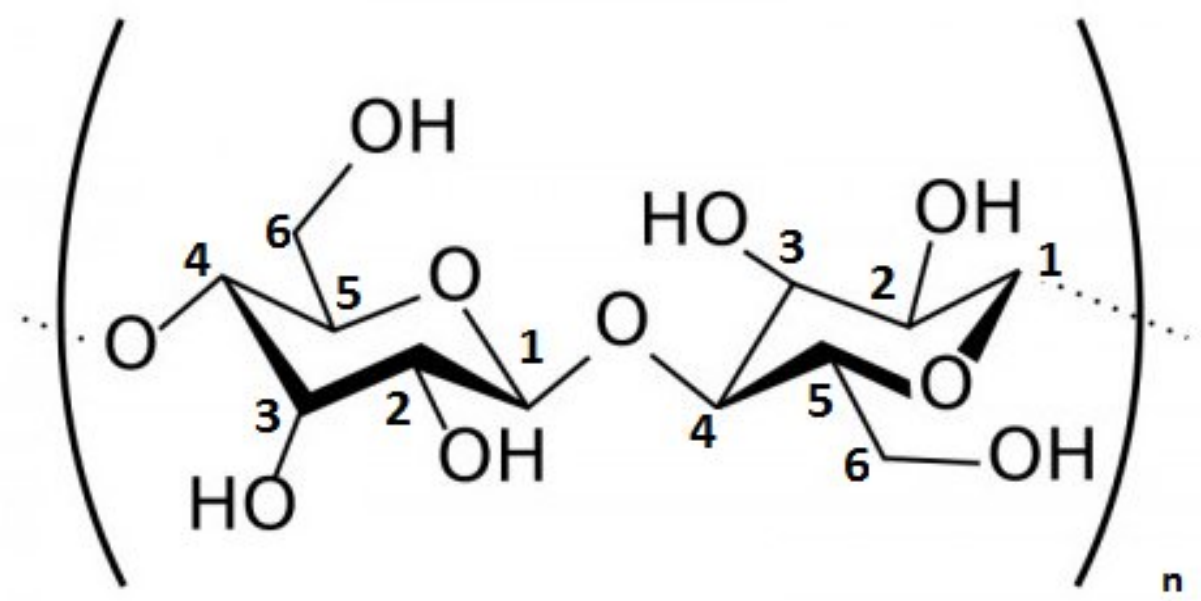

Fig. 1.1: Cellulose Structure

Fig. 1.2 shows in more detail the structure of cellulose, the major structural polysaccharide in plants, and a major component of cell walls. The cell wall of the plants (known as xylem)primarily consists of cellulose and $25 \%$ of lignin which is hard to process unlike cellulose. Cellulose are obtained in the micro fibril forms which are many thin long thread like chain structures held together by $\beta$ 1-4 glycosidiclinkages as shown in the Fig 1.2. Adjacent cellulose chains are held together by the hydrogen bonds, giving them a strong structure. To convert cellulose, $\left(\mathrm{C}_{6} \mathrm{H}_{10} \mathrm{O}_{5}\right)_{\mathrm{n}}$ to $\mathrm{C}_{6} \mathrm{H}_{12} \mathrm{O}_{6}$, the polymer structure at the $-\mathrm{C}-\mathrm{O}-\mathrm{C}$ - $($ Fig. 1.1) needs to be broken. 


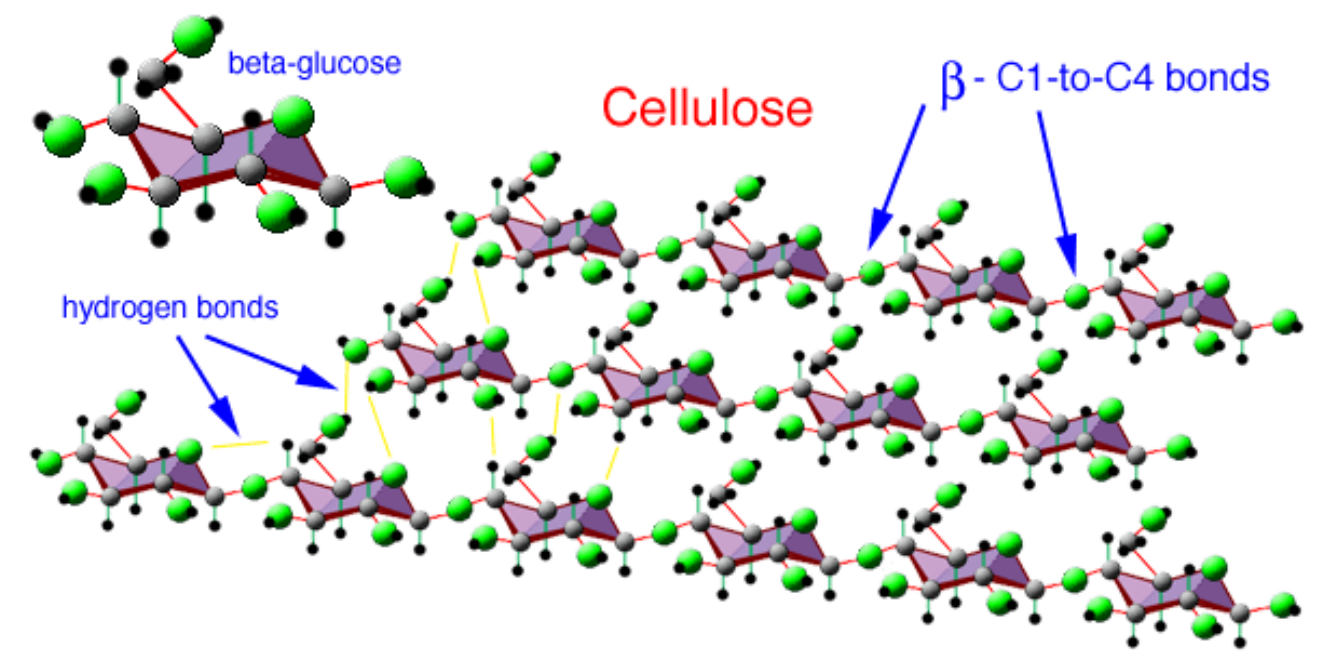

Fig. 1.2: Cellulose structure (adapted from theWebsite of General Biomass Company)

At the crystallographic level cellulose has two structures: cellulose I and cellulose II. Cellulose from less mature biomass such as algae and bacteria has the $\mathrm{I}_{\alpha}$ form with triclinic structure $\left(a=6.717 \AA, b=5.962 \AA, c=10.400 \AA, \alpha=118.08^{\circ}, \beta=114.80^{\circ}\right.$, and $\left.\square=80.37\right)$ whereas cellulose from mature biomass such as plants has the $I_{\beta}$ form with the monoclinic structure $\left(\mathrm{a}=7.784 \AA, \mathrm{b}=8.201 \AA, \mathrm{c}=10.38 \AA, \alpha=\beta=90^{\circ}\right.$ and $\left.\square=96.5^{\circ}\right)$. Cellulose $\mathrm{I}$ can be converted to cellulose II after treatment with $\mathrm{KOH}$ (such as in mercerization of cotton) with the structure of cellulose II being also monoclinic but with different unit cell parameters (Kolpak et al 1978, Mansikkamaki et al 2005). In this thesis, all measurements were carried out on commercially available microcrystalline cellulose (MCC) with the $\mathrm{I}_{\beta}$ structure. It is possible to convert the meta-stable $\mathrm{I}_{\alpha}$ form to $\mathrm{I}_{\beta}$ form using hydrothermal treatments at about $260^{\circ} \mathrm{C}$. In the monomers of cellulose, that is the $\mathrm{C} 1$ and $\mathrm{C} 4$ carbons have the $\mathrm{OH}$ groups attached to it and due to the linkage between $\mathrm{C} 1$ and $\mathrm{C} 4$ these $\mathrm{OH}$ groups graft to form $\mathrm{H}_{2} \mathrm{O}$ and $\mathrm{O}$ atoms. Hence the linkage between $\mathrm{C} 1$ and $\mathrm{C} 4$ has a -O- atom making cellulose a very strong polymer. Hence, cellulose is identified as an example of condensation polymer. Due to the absence of $\mathrm{OH}$ groups or very less $\mathrm{OH}$ groups (Hydroxyl groups), cellulose is insoluble in water. The cellulose structure consists of the branched off carbon chain on the alternating sides hence the straight chains are formed. The cellulose polymers are lined side by side which leads to hydrogen bonding between the chains making them more rigid and increasing the strength. 
Defects in the cellulose chains result from the distortion of the chains in the microfibrils affecting the crystallinity of cellulose. These distortions break crystalline symmetry and produce the amorphous component of cellulose. It is now known that hydrolysis using $\mathrm{H}_{2} \mathrm{SO}_{4}$ can dissolve these amorphous regions thereby producing needle like nanofibrils, called cellulose nanocrystals (CNCs), with length $\approx 100 \mathrm{~nm}$ and width $\approx 10 \mathrm{~nm}$ (dimensions depend on the source of microfibrils). The crystallinity of microfibrils is usually high (90\%) since the amorphous component has been removed. Nanofibrillated cellulose produced by chemical/mechanical or mechanical processes only islabeled as cellulose nanofibrils (CNFs). Finally, HCl-assisted degradation of wood-chip based cellulose fibers led to the formation of commercial microcrystalline cellulose (MCC), an inert product of great value used as a tablet binder in pharmaceuticals, foods and other consumer products. The particle size of MCC is usually around 5 to $10 \mu \mathrm{m}$ (Seehra et al. 2012). All the measurements reported here were done on MCC obtained from a commercial source (Alfa-Aesar) and it was found to have the $\mathrm{I}_{\beta}$ crystal structure.

\subsection{Applications of Cellulose}

Cellulose has been found to be useful in a variety of applications, some of which are listed below.

- Cellulose in biomass is a renewable energy source through combustion and via conversion to ethanol,later used as fuel for automobiles.

- Cellulose is the major constituent of paper and intextiles made from cotton, linen, and other plant fibers which has cellulose in it.

- Cellulose can be used as insulator for building insulation which is environmental friendly and thereby decreasing the green house effects.

- Cellulose is the raw material in the manufacture of nitrocellulose (cellulose nitrate) which was used in smokeless gunpowder.

- Cellulose is used for medicinalpurposes as filler and binders in tablets.

- As an inert material and source of fiber, cellulose is used in a variety of consumer products. 
- Cellulose is a major food source for animals whose gut has the necessary enzymes to convert cellulose to sugars.

\subsection{OBJECTIVES OF RESEARCH}

Renewable energy derived from plants and wood such as cellulose is one of many alternative fuel sources being looked at to replace the fossil fuels that the world is relying on so heavily for energy. One of the factors that make cellulose so appealing is its renewable nature and its abundance as compared to fossil fuels which are limited and so costlier. Conversion of this abundant lignocellulosic biomass to biofuels as transportation fuels presents a viable option for improving energy security and reducing greenhouse emissions as that from fossil fuels. In this research, two experimental techniques viz. ball-milling and hydrothermal treatments are employed in order to breakdown the cellulosic structure for its eventual use as energy source. The specific aim is to determine the minimum conditions for the breakdown of cellulose structure.

The organization of the rest of the thesis is as follows. Chapter II is devoted to description of the experimental procedures used in this work and the major pieces of equipment employed for the analytical characterization of the samples. In chapter III, experimental results obtained on MCC samples ball-milled for different times are presented along with interpretation and discussion of the results. Likewise, in chapter IV, experimental results obtained from the hydrothermal treatment of MCC are presented and discussed. A brief summary of the major conclusions of results obtained in this work are given in chapter $\mathrm{V}$. 


\section{EXPERIMENTAL PROCEDURES AND TECHNIQUES}

\subsection{Introduction}

The phase transformations and the structural characterization of the microcrystalline cellulose (MCC) were determined by analyzing the data from several laboratory techniques. In this chapter, a brief explanation of the experimental techniques and equipments used to thoroughly characterize the pre and post hydrothermally treated (HTT) samples and ball-milled (BM) samples are described.

\subsection{X-Ray Diffraction (XRD)}

$\mathrm{XRD}$ is one of the most important techniques used in the material science industry. It plays a vital role in determining the structures and lattice parameters of the crystals. In this work the degree of crystallinity of MCC of the post ball-milled MCC and hydrothermally treated MCC were determined which provided strong evidence to show that the cellulose is converted from its crystalline form to an amorphous phase for the ball-milled phase. For the hydrothermally treated $\mathrm{MCC}$, transformation of MCC to a different phase is evident under certain conditions.

The diffraction of X-rays of fixed wavelengths $\lambda$ by crystals is illustrated in Fig.2.1. A set of parallel planes containing the atoms of a crystal and separated by distance $d$ are shown. Two parallel rays of X-rays with wavelength $\lambda$ are incident on the parallel planes with incident angle $\theta$. The path difference between the ray diffracted from the top plane and the ray diffracted from the adjoining plane is $\mathrm{AB}+\mathrm{BC}$. Using the geometrical construction shown in Fig 2.1, $\mathrm{AB}=\mathrm{BC}$ $=\mathrm{d} \sin \theta$ yielding the path difference equal to $2 \mathrm{~d} \sin \theta$. When the path difference equals integral multiple of $\lambda$, the constructive interference leads to an intense diffracted beam. This relationship written as

$$
2 \mathrm{~d} \sin \theta=\mathrm{n} \lambda, \mathrm{n}=1,2,3---(2.1)
$$




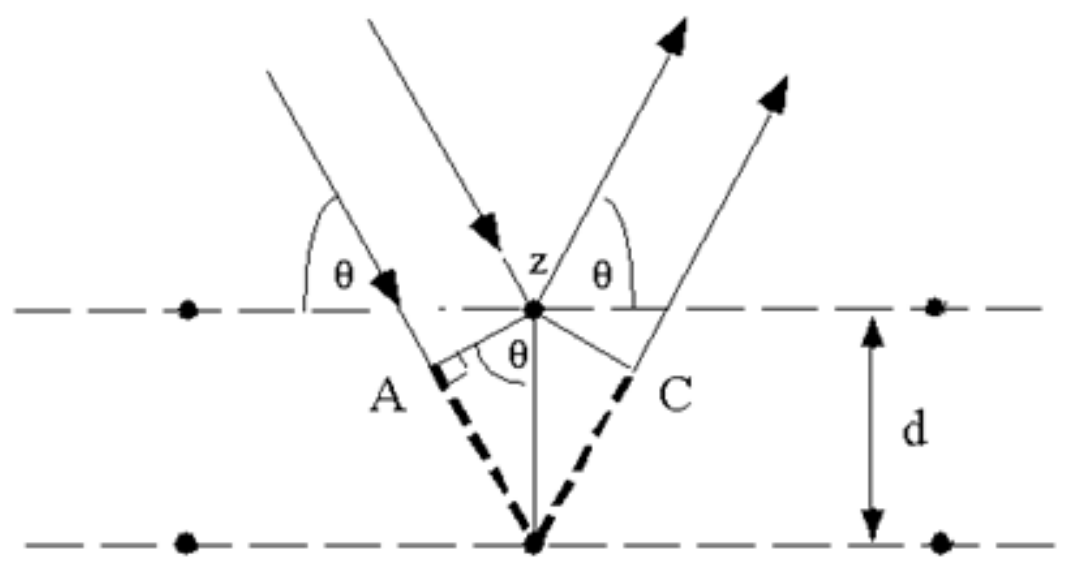

$\mathrm{B}$

Fig. 2.1:Geometry for the explanation of Bragg's Law

is called Bragg's law and it governs the process of X-ray diffraction. In experiments, $\theta$ is varied by rotating the sample as well as the detector. Since, the angle between the incident and the diffracted beams is $2 \theta$, the detector is rotated by $2 \theta$ (see Fig. 2.2). In Eq. (2.1), $\mathrm{n}$ is called the order of diffraction.

The d spacing between successive planes denoted by Miller indices (hkl) depends upon the crystal structure of a material. In order to access all possible planes with different $d_{(h k l)}$ values, the sample is crushed into a fine powder. Micro-crystallites of the powdered sample is then oriented randomly. As $\theta$ is varied, a line appears whenever the Bragg's law for a particular set of parallel planes with $\mathrm{d}_{(\mathrm{h} \mathrm{k} \mathrm{l})}$ is satisfied:

$$
\mathrm{d}_{(\mathrm{h} \mathrm{k} \mathrm{l)}}=\frac{n \lambda}{2 \sin \theta(\mathrm{hkl})}
$$

XRD provides insight into various attributes of the unit cell of a structure. The XRD not only provides information on measurements of degree of crystallinity but also it determines the structures and lattice parameters of crystals. For example, it can be used to determine the crystalline unknowns in solid structures, particle size/ grain size of the crystallites, orientation of single crystals, thermal expansion of individual phases, elastic constants and Debye temperatures, strains and a variety of lattice defects (Cullity 1956). The quantitative analysis of various phases present in a material by XRD has also been discovered. One such method developed was Rietvield analysis used to find the quantitative percentages of the metals/organic/inorganic minerals present in the given material. In our laboratory, this analysis is conducted using the software Jade 9 which includes the inorganic crystal structure database 
(ICSD) thereby matching the generated XRD patterns to the pre-identified existing standard patterns.

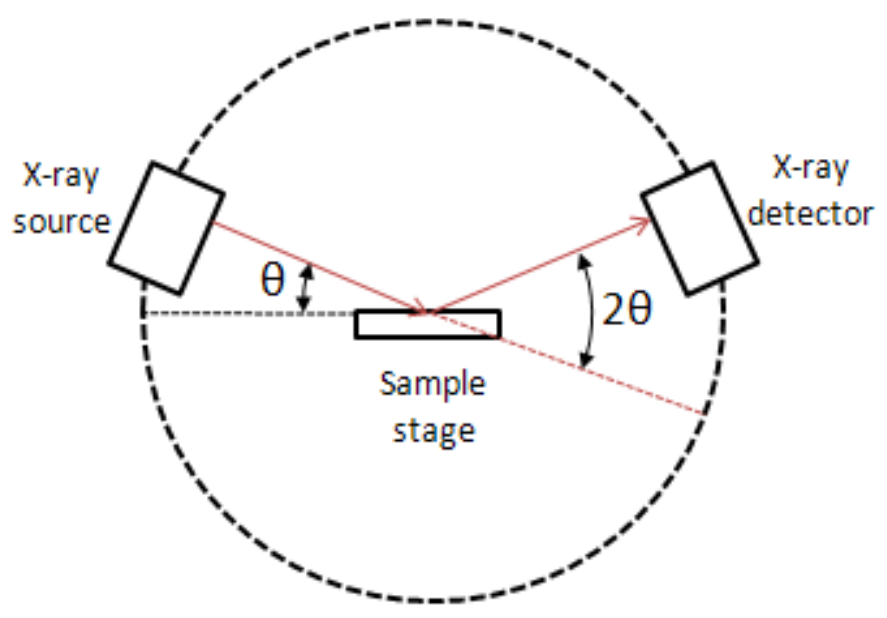

Fig.2.2: Focusing geometry of the diffractometer

\subsubsection{Production of X-rays}

X-rays are the part of electromagnetic spectrum and therefore have properties of both waves and particles. The energy of the electromagnetic beam interacting with the material is partly transmitted, partly refracted and scattered and partly absorbed. X-rays are produced whenever high speed electrons collide with a metal target. In other words X-rays are produced when there is sudden deceleration of fast moving particles. Within the target, the electrons encounter crowds of electrons, which causes a sudden deceleration and hence X-rays are produced. The current fed to the anode heats the filament of the X-ray tube, more the current, the greater the number of electrons that are available to pull across the gap to strike the anode. The anode is water cooled block of copper containing desired target metal.

In thediffractometershown in Fig. 2.3, the X-ray tube emitting X-rays, the goniometer containing the sample and the detector arm are shown. The X-rays diffract after hitting the sample and the X-ray detector counts the number of X-ray photons diffracted at each angle. Distance from the target to the sample equals that from the sample to the receiving slit. The detector rotates $2^{\circ}$ for every degree the sample rotates. The detector transmits the signal to the 
computer where the results are displayed in the real time graph of the diffracted X-ray intensity vs the angle in degrees $2 \theta$ of diffraction of the X-ray beam.

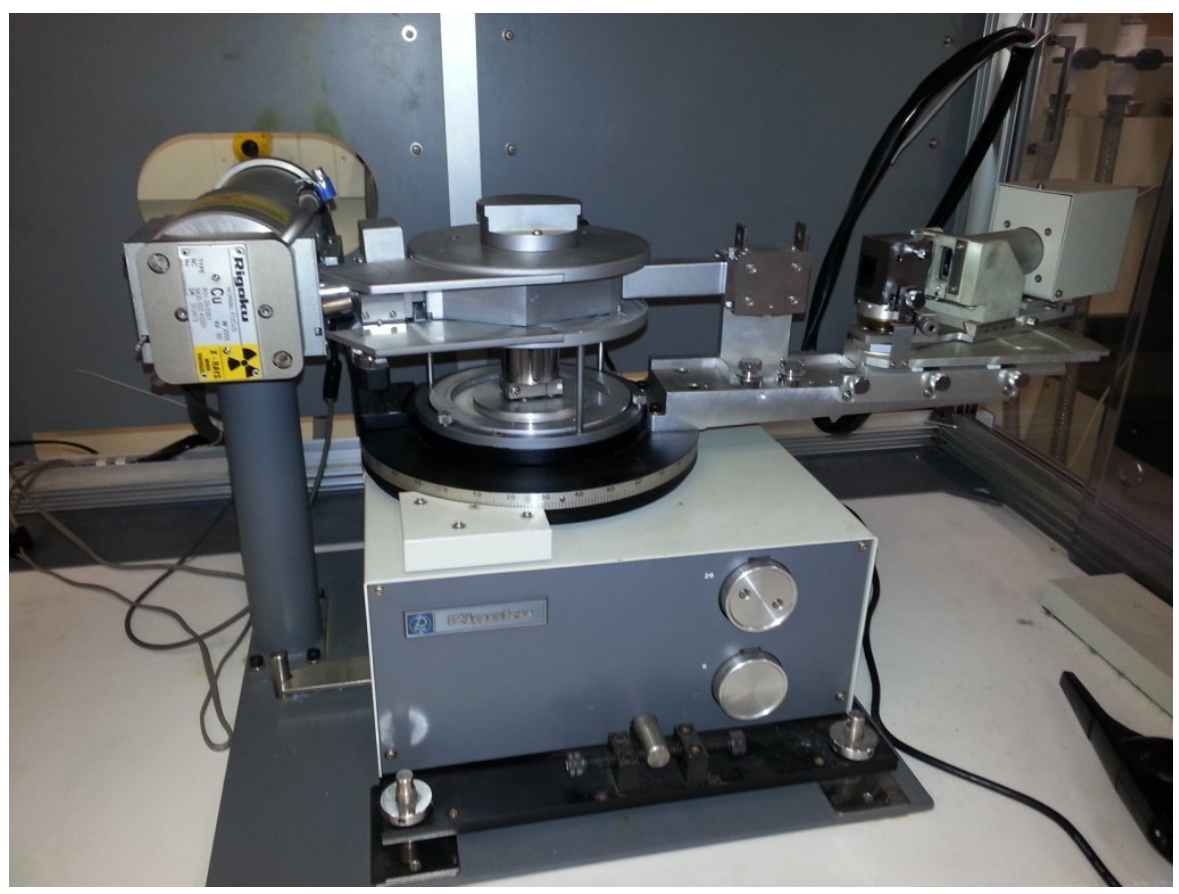

Fig.2.3:Diffractometer of Rigaku D/Max System

X-ray diffraction analysis was performed using a RigakuDiffractometer model D/MAX and monochromatic radiation of the $\mathrm{CuK} \alpha$ lines. As explained earlier, the diffractometer is used to determine the unknown spacing (d-spacing) of crystal plane with a known wavelength of $\lambda=$ $1.5418 \mathrm{~A}^{\circ}$. In the powdered diffraction method, the sample is ground to a fine powder using a mortar and pestle (Fig. 2.4).

The experimental conditions included in the wide angle X-ray diffraction (WAXD) are the $\mathrm{CuK} \alpha$ source with $\lambda=1.5418 \mathrm{~A}^{\circ}$ for the $2 \theta$ range of $10^{\circ}$ to $50^{\circ}$ with $0.05^{\circ}$ steps, 6 s counting time at each step and intensity is measured in counts. The voltage applied to the target was set at $40 \mathrm{KV}$ and filament current was set to $30 \mathrm{~mA}$. The sample prepared using the mortar and pestle was filled on the middle of the sample holder which was pressed flat using ethanol. 

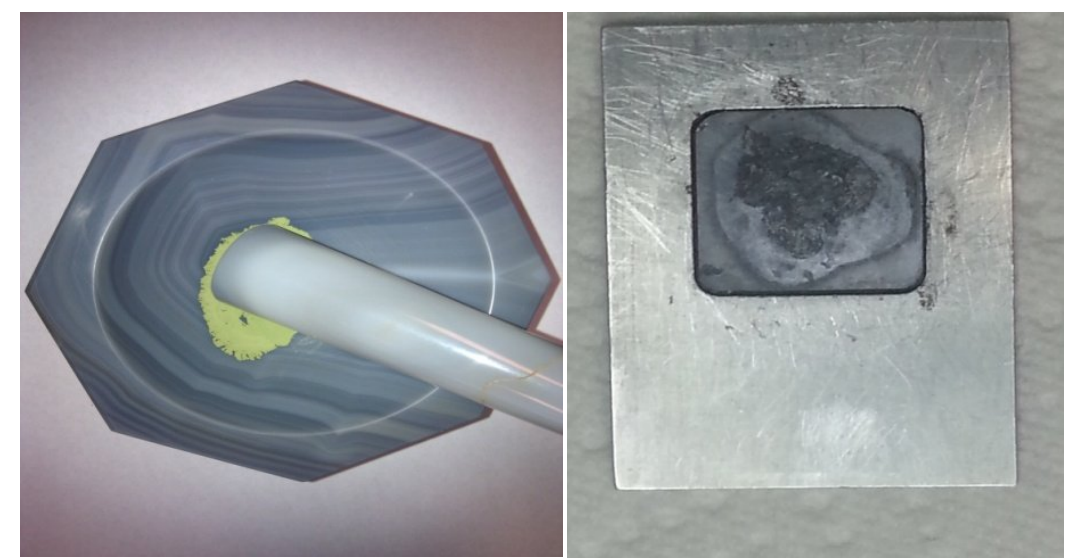

Fig. 2.4: Mortar and Pestle (left) and the sample holder Si plate(right) used in the experiments

Then the sample is placed in the vertical sample holder provided and the protective shielding is closed after verifying that the sample plate is fitted into the sample holder nicely. Later, the chiller is turned on after turning on the water lines and then the X-rays are turned on using the automated computer. Final analyses on the X-ray patterns were carried out using the Jade 9.1 software package purchased from MDI (Materials Data Inc.).

\subsection{Thermogravimetric Analysis (TGA)}

Thermo-gravimetric analysis is an analytical technique used to investigate the change in the weight of a material as a function of temperature. When the materials are subjected to heat, there is a weight loss due to decomposition (breaking apart of chemical bonds), evaporation (loss of volatiles with elevated temperatures) and reduction or desorption. The initial weight-loss observed near $100^{\circ} \mathrm{C}$ is usually due to the moisture present in the material and the major weightloss measured is due to the chemical reactions which liberate gases.(Earnest,1990) 


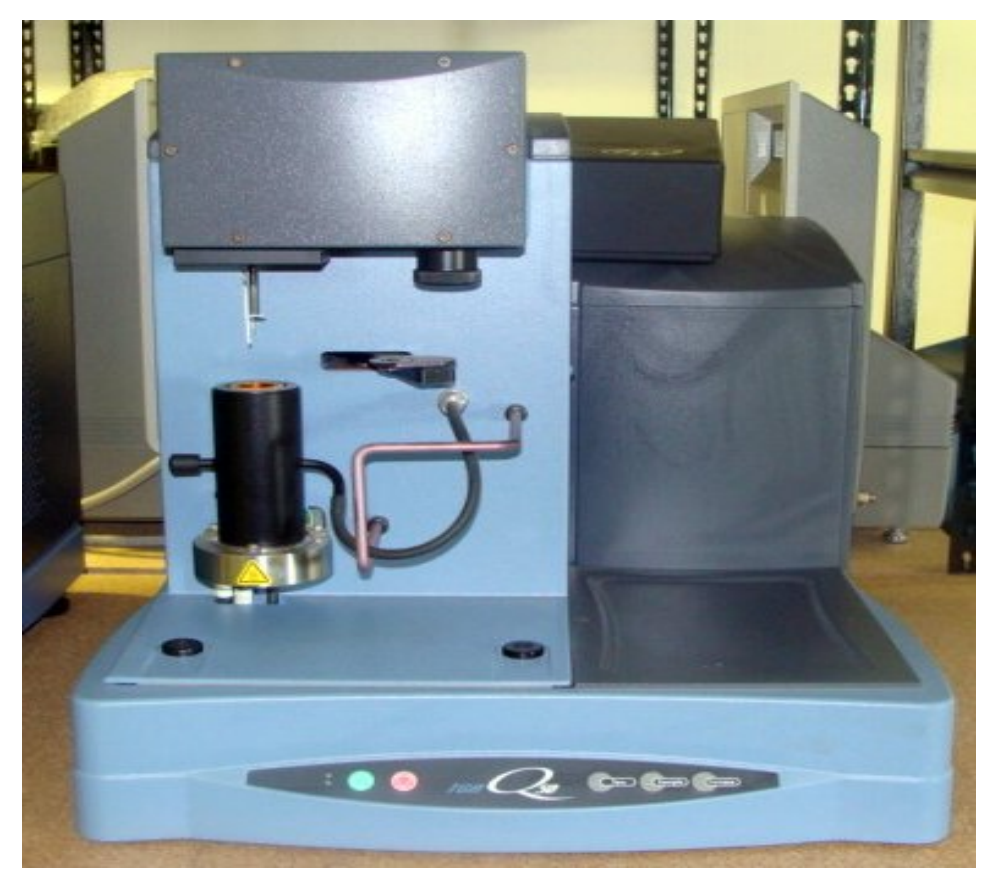

Fig. 2.5: TA instrument TGA Q 50

The TGA system used was a TA instrument model Q50. It consists of a microbalance and the weighing pan is made of platinum with a furnace controlled by the automated computer. This system can also be used as sensitive balance inaddition to the thermo-gravimetric analysis. The sensitivity of the instrument is 100 nano grams. The temperature range of the Q50 is from the room temperature to $1000^{\circ} \mathrm{C}$. The system uses high purity nitrogen for balance purge and sample purge. The balance purge flow is at a rate of $40 \mathrm{~mL} / \mathrm{min}$ and sample purge flow rate is 60 $\mathrm{mL} / \mathrm{min}$ and the heating range of the equipment can be set from $0.01{ }^{\circ} \mathrm{C} / \mathrm{min}$ to $200{ }^{\circ} \mathrm{C} / \mathrm{min}$. These measurements can also be carried out in inert environment such as high purity helium or argon or in some cases air. The weight of the sample is recorded with increase in temperature thereby providing us the information on percentage weight change, temperature at which major amount of weight change occurred and the weight of the final residue. The Figure 2.5 shows the TGA Q50 equipment used in this research.

The ball-milled and HTT samples are loaded onto the Pt sample holder and the furnace is closed using the computerized setup and the weight-loss is recorded in weight (depicted on yaxis) against the temperature changes on $\mathrm{x}$-axis. The data can either be collected from the 
computer or processed in other commercial softwares such as Origin or Microsoft excel or can be modified in the inbuilt feature TGA universal analysis.

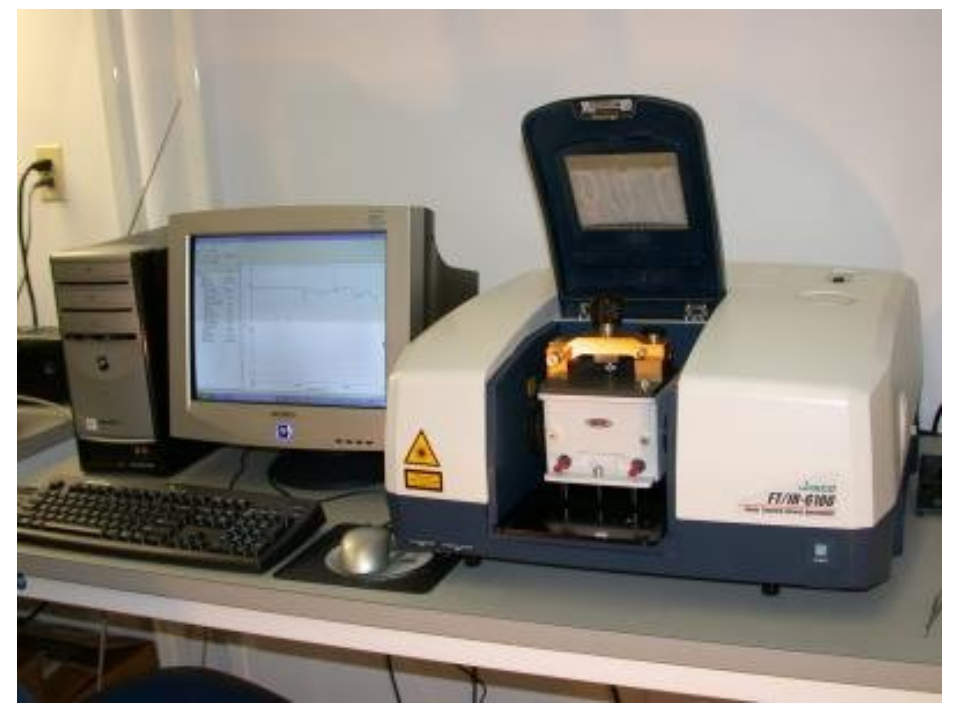

Fig. 2.6: Mattson Infinity Gold FTIR

\subsection{Fourier Transform Infrared (FTIR) Spectroscopy}

Fourier transform infrared spectroscopy (FTIR) is a technique which is used to obtain an infrared spectrum of absorption of a sample. The term Fourier transform infrared spectroscopy originates in the fact that a Fourier transform which is a complex mathematical computation is required to convert the raw data into the actual spectrum. In our system, the spectral range covered is from $400 \mathrm{~cm}^{-1}$ to $4000 \mathrm{~cm}^{-1}$. Infrared, an invisible part of the electromagnetic spectrum between the visible light and microwaves, refers to the radiation used by the spectrometer to perform its measurements. The goal of FTIR is to measure how well a sample absorbs light at each wavelength. The working technique of the FTIR is to shine a beam containing many frequencies of light at once and measure how much of that beam is absorbed by the sample. Next, the beam is modified to contain a different combination of frequencies giving a second data point.This process is repeated many times; later the system collects all the data and plots absorption on Y-axis and wavelengths on X-axis (Smith et al 2011). A photograph of the system is shown in Fig. 2.6. 


\subsubsection{Working Principle}

The interferometer shown in Fig. 2.7 works as follows. An infrared energy is emitted from the source and travels through the optical path of spectrometer. The electromagnetic rays travel first to the interferometer where they are split and recombined to produce an encoded interference pattern which is called an interferogram. The interferometer consists of a fixed position mirror, a moving mirror and a beam splitter where there is $90^{\circ}$ angle between the incoming and the outgoing beam as shown in theFig. 2.7

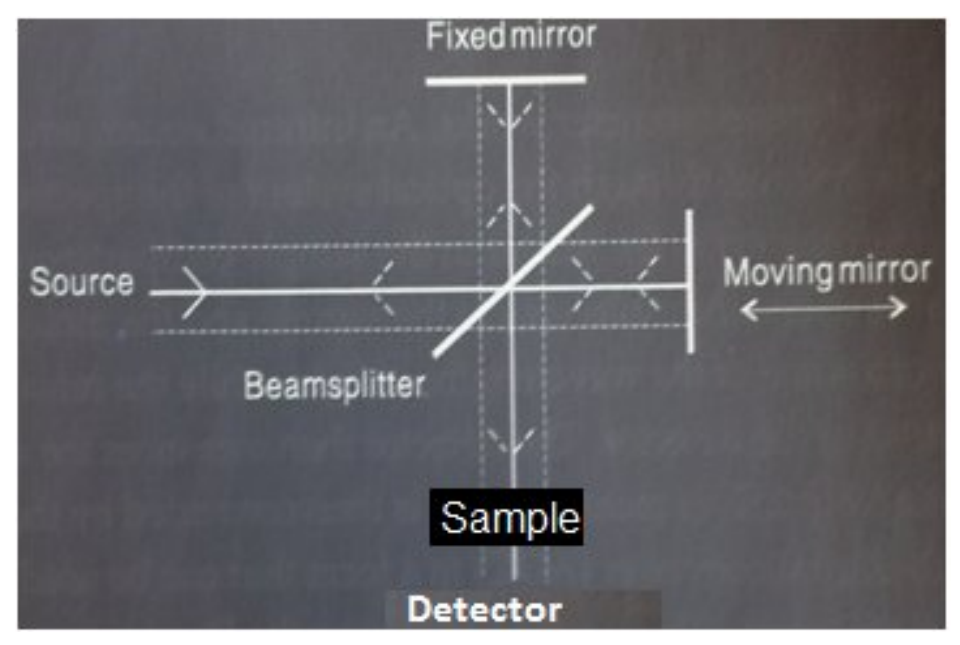

Fig.2.7: Interferometer

Infrared energy is transmitted from the source via mirrors to the beam splitter where almost $50 \%$ off the beam intensity is reflected towards the fixed position mirror and the other $50 \%$ to the moving mirror. The returning beam from each mirror travels back to the beam splitter where two mixed are recombined and the $50 \%$ of this light is then directed towards the sample compartment and the rest returns to the source. From the sample, the infrared light travels to the detector where the remaining light is measured and an interferogram is produced. The interferogram is the time domain representation of the interference pattern which is produced through the ADC (Analog to Digital Converter) which converts the measurement to digital format which can be used by computer. Later a fast Fourier transform (FFT) converts the interferogram to a single beam spectrum, which is the representation of the same information in the frequency domain. The FTIR process is illustrated in figure 2.8 


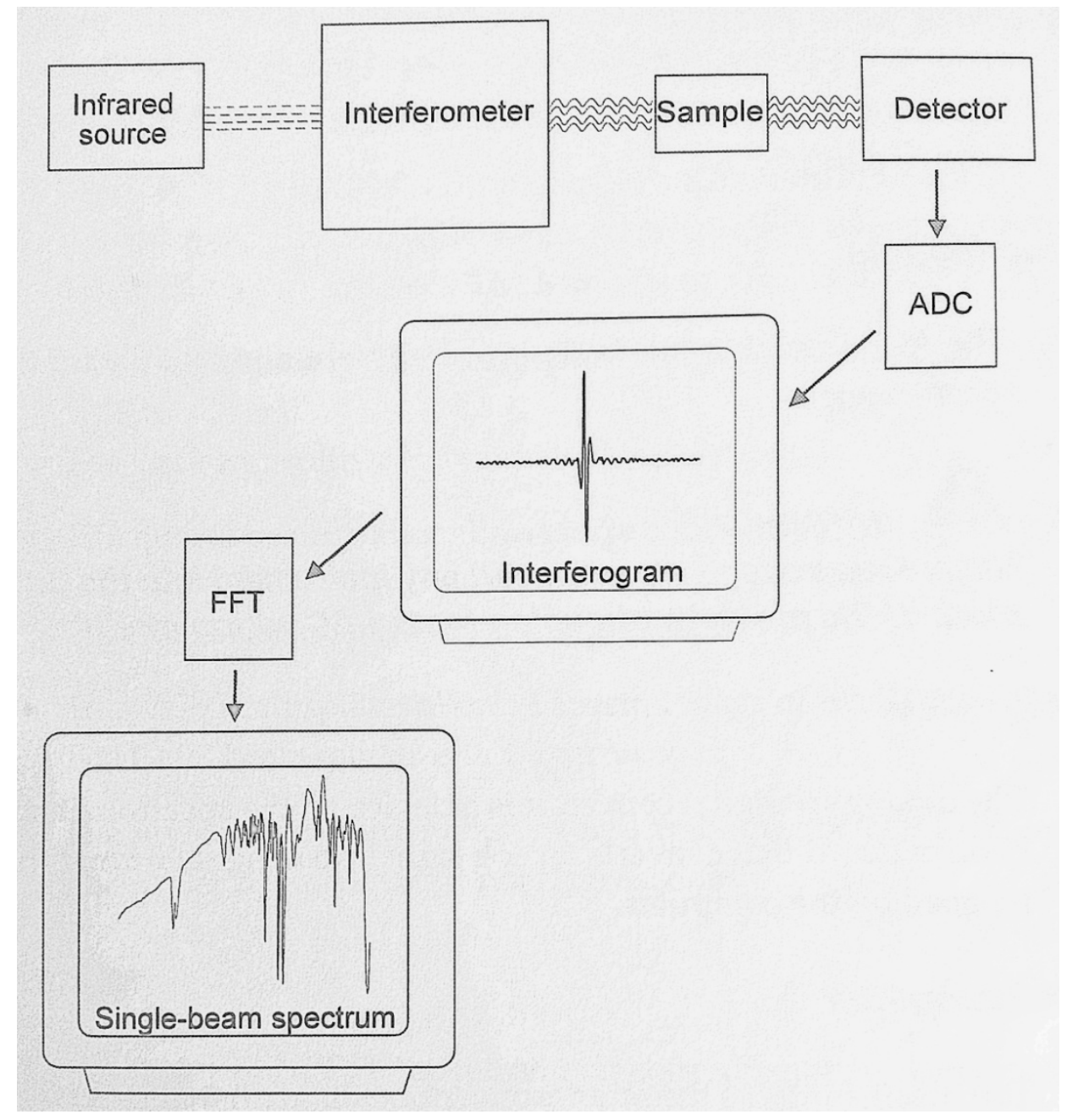

Fig.2.8:The schematic of the FTIR process

\subsubsection{Sample Preparation}

FTIR spectroscopy experiments were performed on Mattson Infinity gold FTIR spectrometer. The FTIR spectra in our work were acquired by theKBr pellet method of sample preparation. To analyze the data on the BM or HTT samples,samples were mixed with $\mathrm{KBr}$ powder in proportions of $\mathrm{KBr}$ :sample $=95: 5$ and grinded and the mixture is pressed into a thin disk through which light is easily transmitted. The thin-disk samples were placed on a sample holder (max size of $0.7 \mathrm{~mm}$, diameter by $9.0 \mathrm{~mm}$ deep) and the sample is inserted in the sample 
chamber where the IR radiations were focused. These experiments were carried out using software called WINFIRST which helps in analyzing and modifying the data.

\subsection{Scanning Electron Microscopy (SEM)}

Scanning electron microscopy is a special variety of electron microscopy that produces images of a sample by scanning it with a focused beam of electrons. These electrons interact with the electrons present in the sample, producing various signals that can be detected and that contain information about the samples surface topography and composition. SEM is capable of achieving resolutions down to about $100 \mathrm{~nm}$.

For conventional imaging in the SEM, samples should be electrically conductive, at least at the surface and electrically grounded to prevent the accumulation of electrostatic charge at the surface. In general, metallic samples need not be coated prior to imaging in the SEM because they are conductive and provide their own pathway to ground. These measurements were done at the National Energy Technology Laboratory with the assistance of Mr. James Poston.

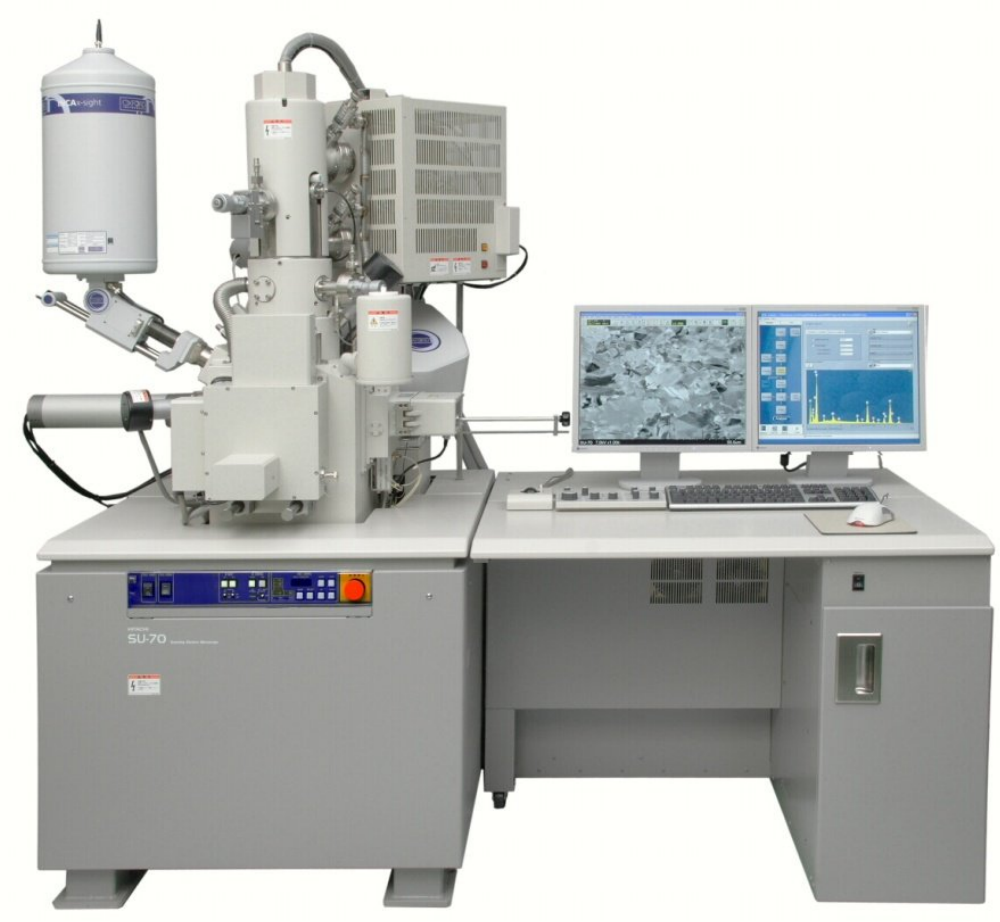

Fig.2.9: Scanning Electron Microscope 


\subsection{Surface Area Measurements}

BET (Brunauer - Emmett- Teller) surface area analysis was carried out in our laboratory on Autochem 2620 purchased from Micromeritics Inc. The main purpose of conducting these experiments is to calculate total pore volume $\left(\mathrm{m}^{3} / \mathrm{g}\right)$, surface area $\left(\mathrm{m}^{2} / \mathrm{g}\right)$ and monolayer volume $\left(\mathrm{cm}^{3} / \mathrm{g}\right)$. Generally, smaller the particle size, higher the surface area. BET theory aims to explain the physical adsorption of gas molecules on a solid surface and serves as the basics for an important analysis technique for the measurement of specific area of materials.

BET analysis provides information on the precise specific area evaluation of materials by Nitrogen multilayer adsorption measured as a function of relative pressure using a fully automated analyzer. The technique encompasses external area and pore evaluations to determine the total specific area in $\mathrm{m}^{2} / \mathrm{g}$ yielding important information on surface porosity and particle size.

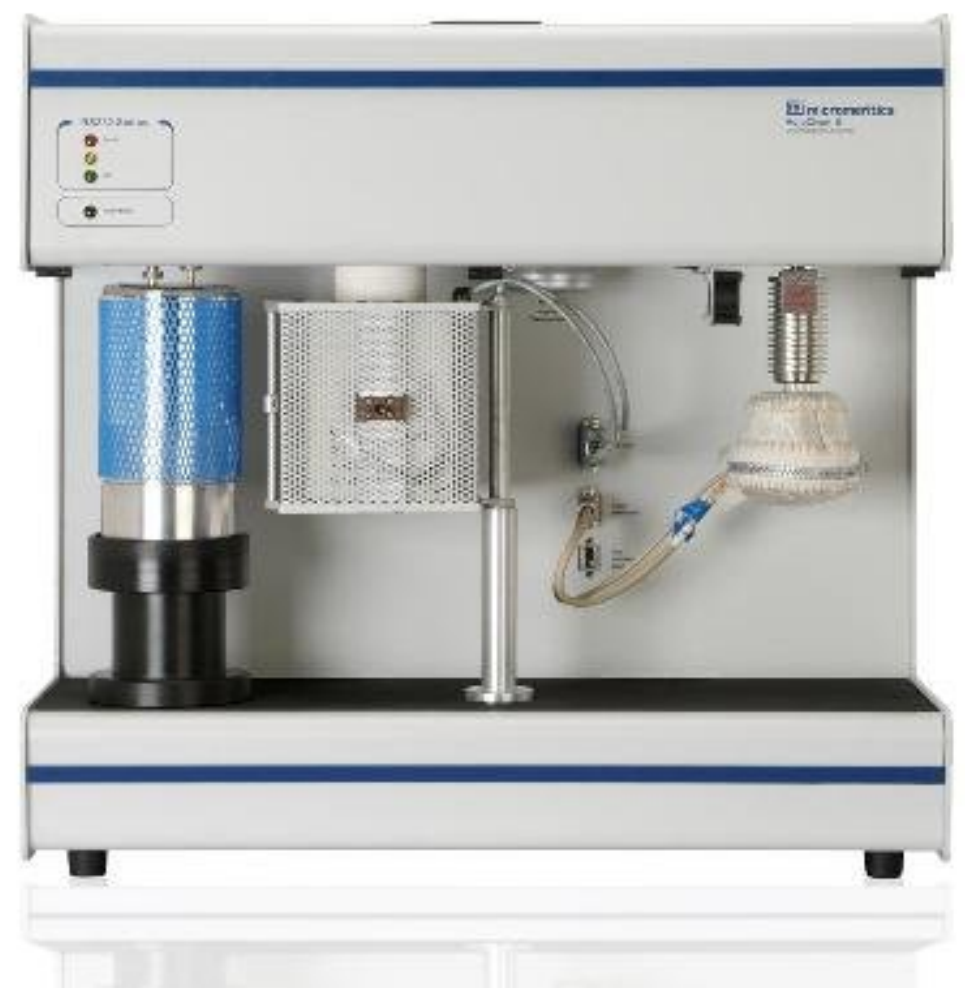

Fig. 2.10:Autochem II 2920 used for surface area measurements 


\subsubsection{Procedure for measuring surface areas:}

The Autochem 2620 is connected to the nitrogen and helium cylinders. Operation of the nitrogen cylinder is done using pressure valves. Firstly, the left pressure valve is checked to be closed completely and then right value is openedslowly which is directly connected to the nozzle of the cylinder such that the pressure is maintained at 2500 PSI minimum. Now, second valve is opened to maintain a pressure of 16 PSI in the left valve. Similarly, pressure is maintainedin the compressed helium cylinder at 200 PSI/ 12 PSI. Sample preparation is done with a clean quartz tube and carefully quartz wool was prepared asa round ball and the quartz wool was pushed to the bottom of the quartz tube which has the larger diameter. It was made sure that quartz wool doesn't block the quartz tube. Position the quartz wool such that at airflow in the tube could be maintained. Sample is then added on to the quartz wool which is used for measuring the surface area. Usually $33 \mathrm{mg}$ of sample must be used. Screws are added to the tube so that it can be connected to the middle chamber which has the furnace, so that the sample can be heated. Autochem switch is turned on and the Autochem software is started. Analysis is started only after the temperature of the furnace is reached to $100^{\circ} \mathrm{C}$ and and then the air valve was maintained at 20 PSI and it was made sure that the nitrogen and helium cylinders were maintained at specified pressures. The pressures of the nitrogen and helium cylinders were maintained at the specified rate throughout the experiment. The software prompts for immersion

of quartz tube in liquid nitrogen so that the temperatures of the materials can be brought down to approximately $-196^{\circ} \mathrm{C}$ and then the quartz tube has to be introduced in water which is at room temperatures to perform physorption and adsorption. After the experiment is terminated the software automatically calculates the surface area, total pore volume and monolayer volume. It is also capable of determining saturated pressure $\mathrm{mmHg}$, ambient pressure $\mathrm{mmHg}$ and crosssectional area $\mathrm{nm}^{2}$. The software also plots TCD (thermal conductivity detector) signal (a.u) vs. time which is very important in identifying and understanding the peaks. 


\subsection{Hydrothermal Treatment (HTT)}

To study the phase transformation and structural changes of MCC, the MCC sample was subjected to HTT. Equipment and procedures involved in preparation of the autoclaved samples are explained below.

\subsubsection{Sample Preparation:}

The samples investigated in this work include microcrystalline cellulose (MCC) which was purchased from the Alfa-Aesar (Product \#A17730). The acquired MCC was subjected to hydrothermal treatment (HTT) using an autoclave (Parr Instruments, Model 4766) and distilled water as solvent. Fig. 2.11 shows the equipment used for autoclaving.

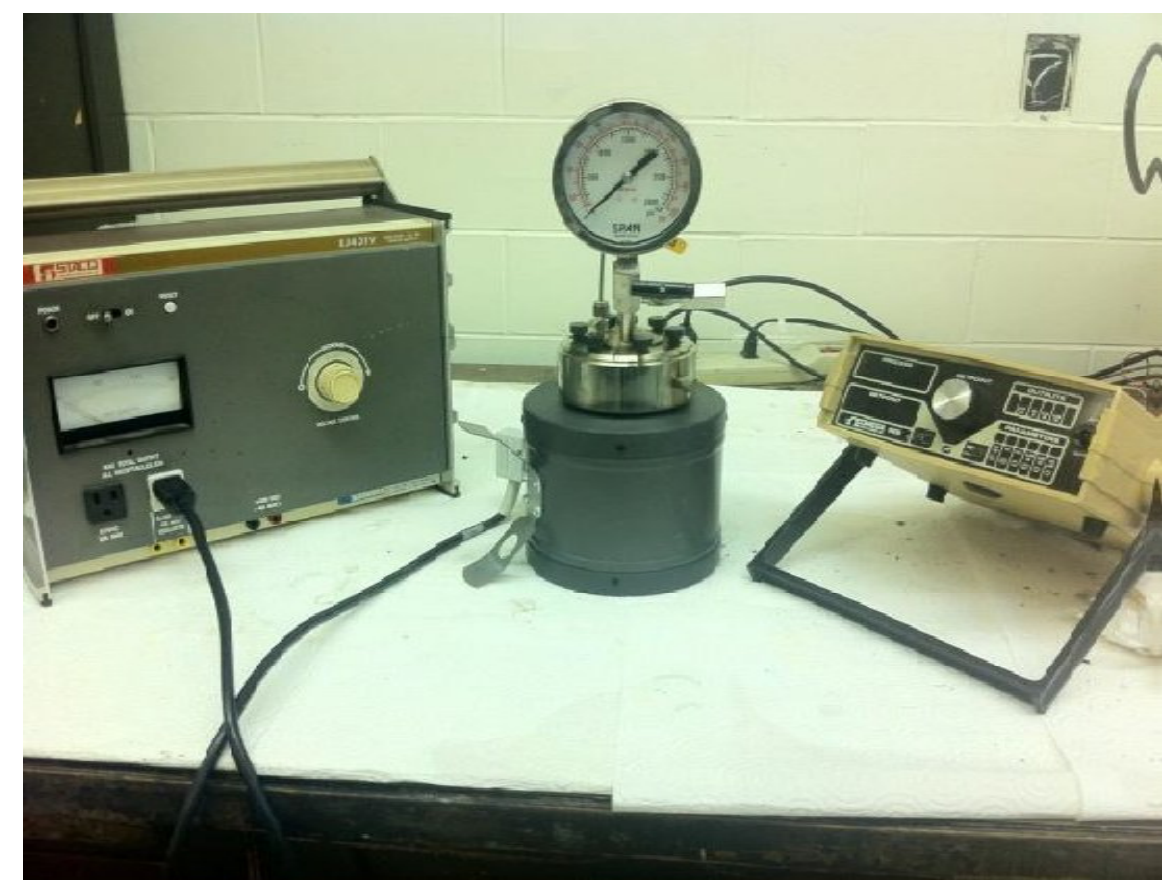

Fig. 2.11: Hydrothermal Setup

For each experiment, $10 \mathrm{~g}$ of the fresh MCC powder with $70 \mathrm{ml}$ of distilled water were sealed in the autoclave and heated with temperature $(\mathrm{T})$, pressure $(\mathrm{P})$ and time $(\tau)$ as the variables and $\mathrm{P}$ and $\mathrm{T}$ controlled by varying the voltage applied to the heater surrounding the 
autoclave.The voltage controller used was isolated AC/DC power supply which was connected to the autoclave and the voltage was increased at a rate of 10 volts for every five minutes until the temperature reached $250^{\circ} \mathrm{C}$ and later $250{ }^{\circ} \mathrm{C}$ temperature was maintained for different times for different samples; in parallel to this the high pressure builds up in the autoclave which was generated from the evaporation of water and perhaps by the decomposition of MCC. These high pressures were recorded on the pressure gauge connected to the autoclave. The temperature in the autoclave was measured using a thermocouple which was externally connected to a DC multi voltmeter calibrated in temperature (see Fig. 2.11). After maintaining the desired temperatures and pressures for particular time, the voltage was decreased periodically at higher rates and finally voltage is turned off. It takes certain amount of time for the temperature in the autoclave to cool down to room temperature and gauge pressure of 0 psi. The temperature/pressures vs time graphs of all the samples were plotted. Fig 2.12 and Fig 2.13 show the TP $\tau$ graphs for converted, partially converted and unconverted samples.

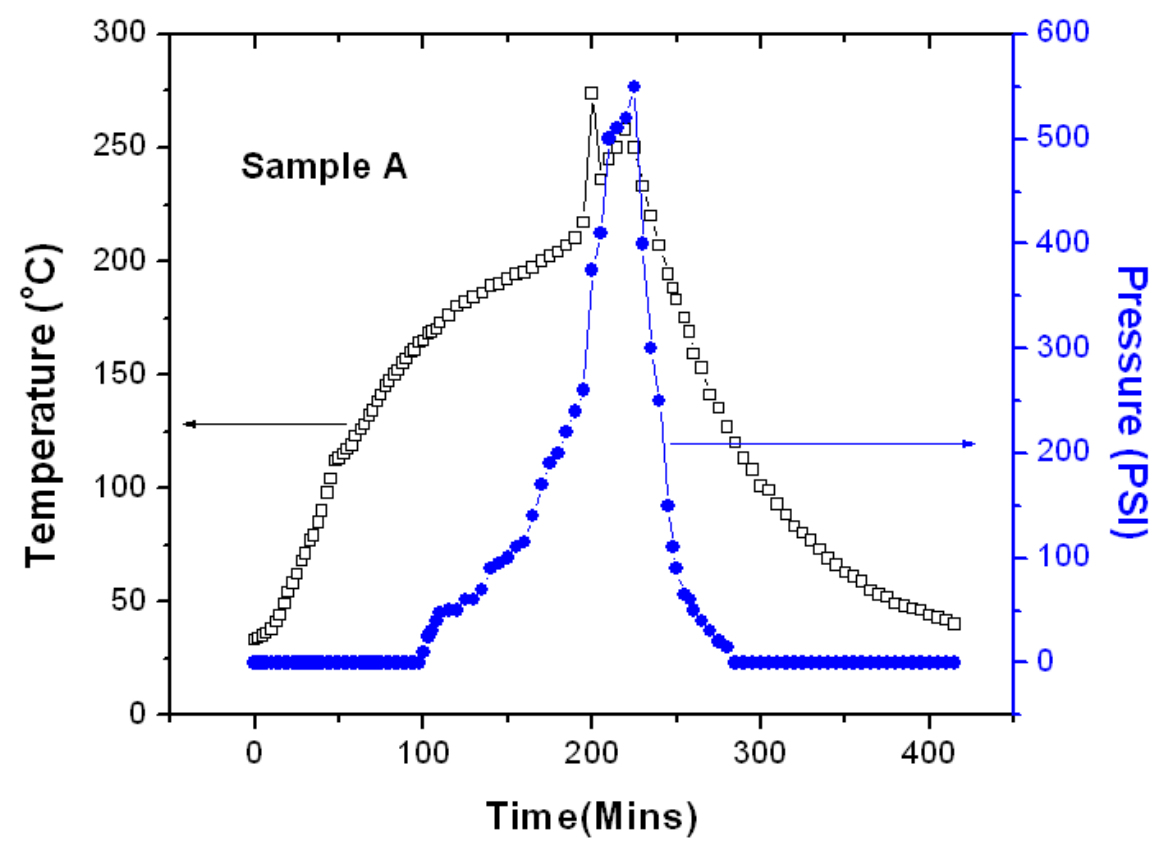

Fig. 2.12:TP $\tau$ graph for sample A (converted)

From the graph we can infer that the sample A was subjected to HTT for almost 400 minutes and it took about 200 minutes to reach $250{ }^{\circ} \mathrm{C}$. The temperature was maintained at $250^{\circ} \mathrm{C}$ for about 30 minutes by limiting the pressures to a maximum of $560 \mathrm{psi}$ by controlling the voltage. After maintaining the temperature for 30 minutes at $250{ }^{\circ} \mathrm{C}$, the voltage is brought down to zero and slowly the pressures in the autoclave start to fall and autoclave is self cooled without 
any external interference. When the pressure is normalized and the temperature reaches room temperature, the autoclave is then unsealed to recover the samples. The obtained sample is subjected to centrifugation. The equipment used for centrifugation isshown in Fig 2.14.
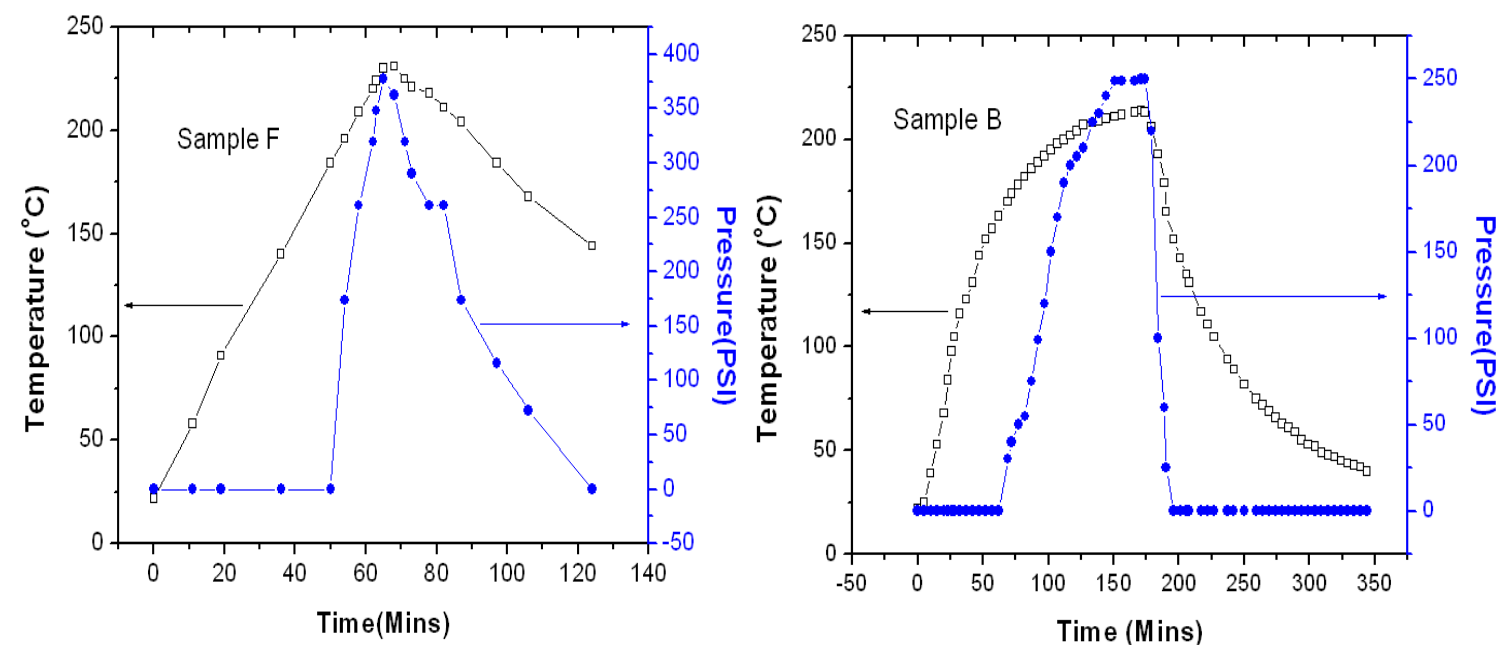

Fig.2.13:TP $\tau$ graph for partially converted sample F\&uncoverted sample B

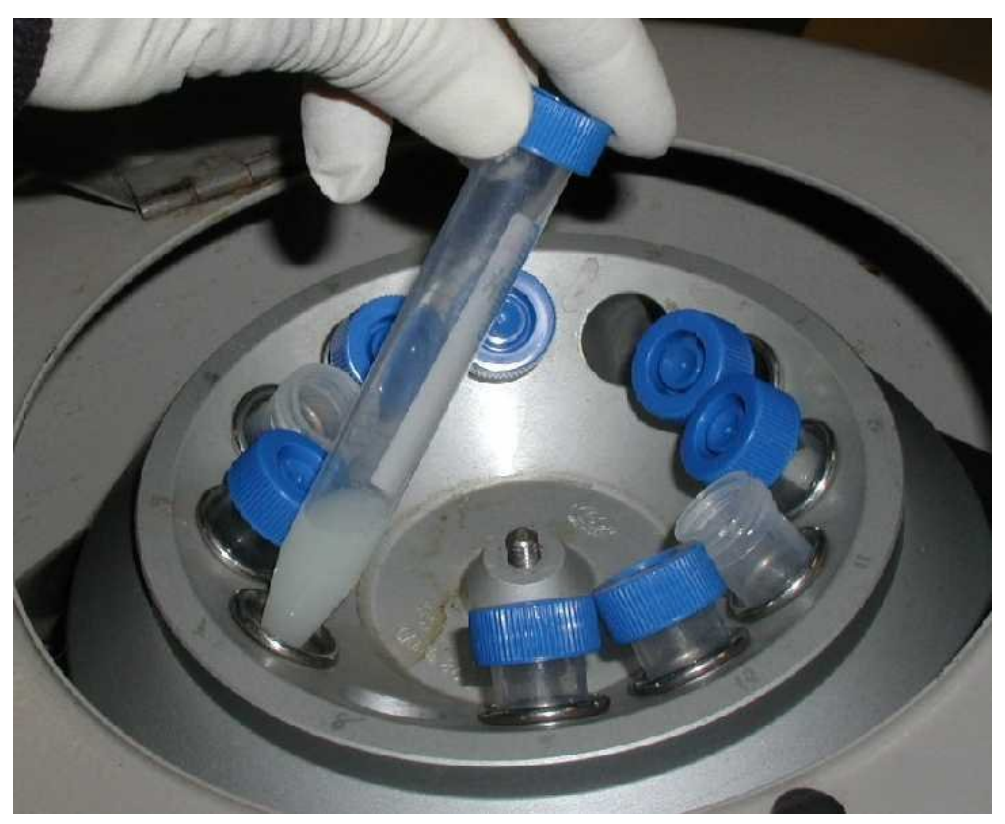

Fig 2.14 Centrifuge technique used in Lab

Centrifuging is done to separate the solid material from the liquid material. Centrifuge works on the sedimentation principle i.e the tendency for the heavier particles in suspension to settle out of the fluid in which they are entrained, and come to rest against a barrier. Centrifuge has a drum rotating its axle called bowl, driven by a motor. The retained material from the autoclave is filled 
in a small bottle and placed in the bowl. Parallel to it another bottle is filled with water and placed in the opposite corner of bowl so that the weights in the bowl are balanced. Speed of the motor can be controlled using the rpm knob. The bowl rotates with the same rpmas the motor rpm. Due to this high speed rotation of the drum, the denser particles (solid material) are settled at the bottom leaving the less dense particles (liquid material) on top.In our experiments the solid material was retained and air dried it over-night. Finally, the solid material was saved and analyzed. This experiment was repeated and a total of nine samples were processed.After air drying the samples, the percentage yield was calculated using Eq. (2.3):

$$
\text { Percentage yield }=\frac{\text { FinalWeight }}{\text { InitialWeight }} * 100
$$

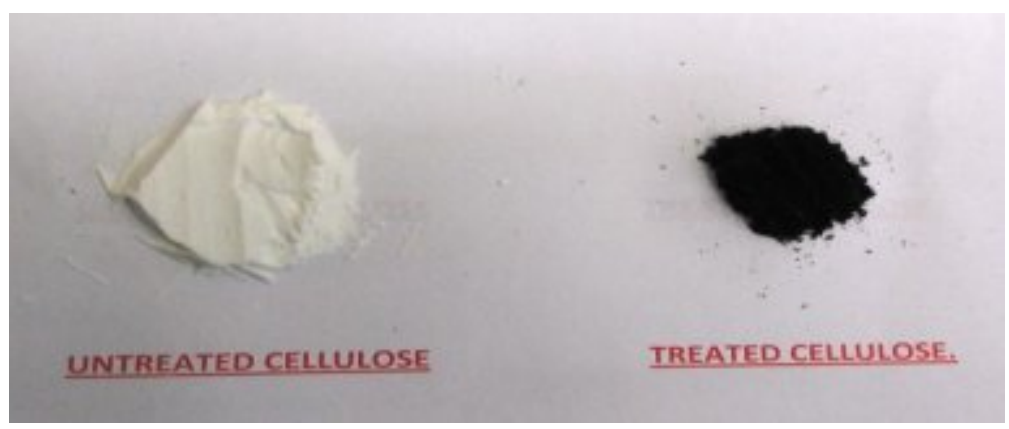

Fig 2.15 Shown is the comparison of samples before and after hydrothermal treatment.

The treated and untreated samples of microcrystalline cellulose were tested for the crystallinity by XRD. Depending upon the magnitudes of $\mathrm{P}, \mathrm{T}$ and $\tau$, some samples lost crystallinity, some were partially converted and few others remained unconverted. The surrounding gaseous medium in the autoclave was either air or helium gas. When using helium gas, an ultra pure helium cylinder is connected to the autoclave through a pipe and a pressure of $10 \mathrm{psi}$ is maintained for 2 minutes inorder for the helium gas to be occupied in the autoclave thereby pushing the air from the open end of the autoclave. After 2 minutes, the autoclave is sealed so that the helium is trapped inside the chamber. 


\subsection{BALL MILLING:}

Ball milling is a procedure which grinds the samples by placing them in a closed cylinder along with one or more grinding balls and imparting motion to the cylinder. Generally, the container and grinding balls are made up of same material; in our case the material used was tungsten carbide. As the cylinder is swung by the externally connected motor, the inertia of the grinding elements causes them to move independently, into each and against the container wall thereby grinding the sample placed in the cylinder. The miller is able to rapidly shake the container back and forth several thousand times a minute. A timer knob is connected to the miller which displays the ball milling time in minutes and push buttons for start and stopping the miller are included. During the run, the timer knob counts down the time remaining in minutes.

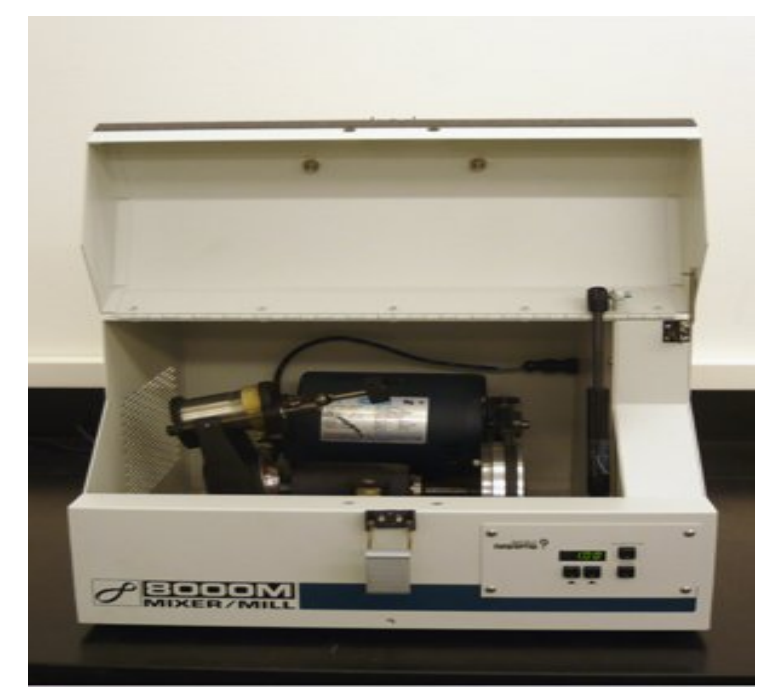

Fig. 2.16:Spex 8000 Mixer Mill

\subsubsection{Procedure used for ball-milling:}

Plug in the power cord of the ball-mill to the electrical inlet. After loading each vial with the MCC sample to be mixed or ground, place it in the cylinder holder. Tighten the cylindrical holder with the knob and lock the holder with the locking tab. Then close the lid and fasten the main latch. Two vials of approximately same weight must be run together to keep the cylindrical container in balance and avoid excess vibration. Program the time setting as desired 
by adjusting the knob. Start the miller after everything is locked and the lid is closed. During the run, the milling timer will count down and display the time left in minutes. When the run is over, the lid latch will disengage with an audible click and the timer is set back to zero. Now open the lid, loosen the locking tabs, open the clamps and remove the vials and store the grinder or milled sample for further analysis. Due to the very strong characteristics of the tungsten carbide balls and cylinder, it is capable of grinding solid rocks or hard particles.

This sample was ball-milled in air for different time $t_{\mathrm{BM}}$ using the Spex 8000 Mixer/Mill. (Fig.2.16) For each experiment, $1.5 \mathrm{~g}$ of fresh $\mathrm{MC}$ and two tungsten carbide balls each of diameter $=11.2 \mathrm{~mm}$ and weight $=10.77 \mathrm{~g}$ were placed in a tungsten carbide vial for milling at 1425 RPM. After ball-milling for a certain time $t_{\mathrm{BM}}$, wide-angle $\mathrm{x}$-ray diffraction (WAXD) patterns of the samples were acquired using a Rigakudiffractometer (Model D/Max, CuKasource with $\lambda=1.5418 \mathrm{~A}$ ) for the $2 \theta$ range of $10^{\circ}$ to $50^{\circ}$ with $0.05^{\circ}$ steps, $6 \mathrm{~s}$ counting time at each step and intensity measured in counts. Micrographs of the samples were acquired by scanning electron microscopy (SEM) using a JEOL 7600 FE-SEM system at the National Energy Technology Laboratory. The IR spectra shown here were acquired using the standard $\mathrm{KBr}$ pellet method and an FTIR spectrometer (Mattson Infinity Gold FTIR spectrometer). The Thermogravimetric analysis (TGA) of the samples was done in flowing nitrogen gas at the heating rate of $10{ }^{\circ} \mathrm{C}$ per minute using the system acquired from TA Instruments (Model TA Q50). 


\section{EXPERIMENTAL RESULTS ON BALL-MILLED CELLULOSE}

\subsection{Introduction:}

Microcrystalline cellulose (MCC) was ball-milled for upto 120 minutes as described in Chapter II. In this chapter, results obtained from the characterization of the ball-milled samples for different times $t_{\mathrm{BM}}$ utilizing the techniques of $\mathrm{x}$-ray diffraction, thermo-gravimetric analysis, scanning electron microscopy and FTIR spectroscopy are presented.

\subsection{X-ray Diffraction:}

Room temperature wide-angle XRD scans of the MCC and ball milled cellulose for different times, obtained by using a Rigaku (D-Max) diffractometer with $\mathrm{CuK}_{\alpha}$ source (wave length, $\lambda=0.15418 \mathrm{~nm}$ ) are shown in Fig 3.1. MCC is normally crystalline in nature yielding sharp lines characteristics of its monoclinic unit cell (Segal. 1959). In Fig 3.1, the Miller indices (hkl) listed next to sharp lines observed for the untreated cellulose are based on this structure.It is evident that with increase in ball-milling time, the Bragg peaks broaden and eventually merge into a single broad halo characteristic of an amorphous phase. This represents the most direct evidence of the breakdown of the cellulose crystalline structure under the ball-milling conditions used in our experiments. Furthermore, the observation of even weakest lines in the XRD pattern of the MCC sample suggests the high degree of crystallinity (85\% - measured using Segal Method) and purity of this cellulose sample. It can also be observed that for the sample ballmilled for $120 \mathrm{~min}$, the broad peak is shifted slightly to the lower $2 \theta$ values $\approx 18^{\circ}$.

The sample crystallinity, $\mathrm{X}_{\mathrm{CR}}$, is defined as the ratio of amount of crystalline cellulose to total amount of sample. Cellulose crystallinity index $X_{C R}$ is estimated by the Segal method (Segal et al 1959) using the Equation:

$\mathrm{X}_{\mathrm{CR}} \%=\frac{I(200)-I(a m)}{I(200)} * 100(3.1)$

Here $I_{200}$ is the peak height of the (200) line at $2 \theta \simeq 22^{\circ}$ and $I_{a m}$ is the amorphous component measured at the minimum near $2 \theta \simeq 18^{\circ}$ (between the (102) and (110) peaks) in Fig 3.2. Both the broadening of the Bragg lines in Fig 3.2 and decrease in $\mathrm{X}_{\mathrm{CR}}$ with increased ball milling time 
$t_{\mathrm{BM}}$ show a rapid decrease in the crystallinity of cellulose so that at $\mathrm{t}_{\mathrm{BR}} \simeq 30 \mathrm{~min}, \mathrm{X}_{\mathrm{CR}}$ essentially becomes negligible (Fig. 3.3). For the sample ball-milled for 60 and 120 minutes, the (200) peak and the minimum near $2 \theta \approx 18^{\circ}$ cannot be located. Hence for these samples, $\mathrm{X}_{\mathrm{CR}}$ could not be determined.

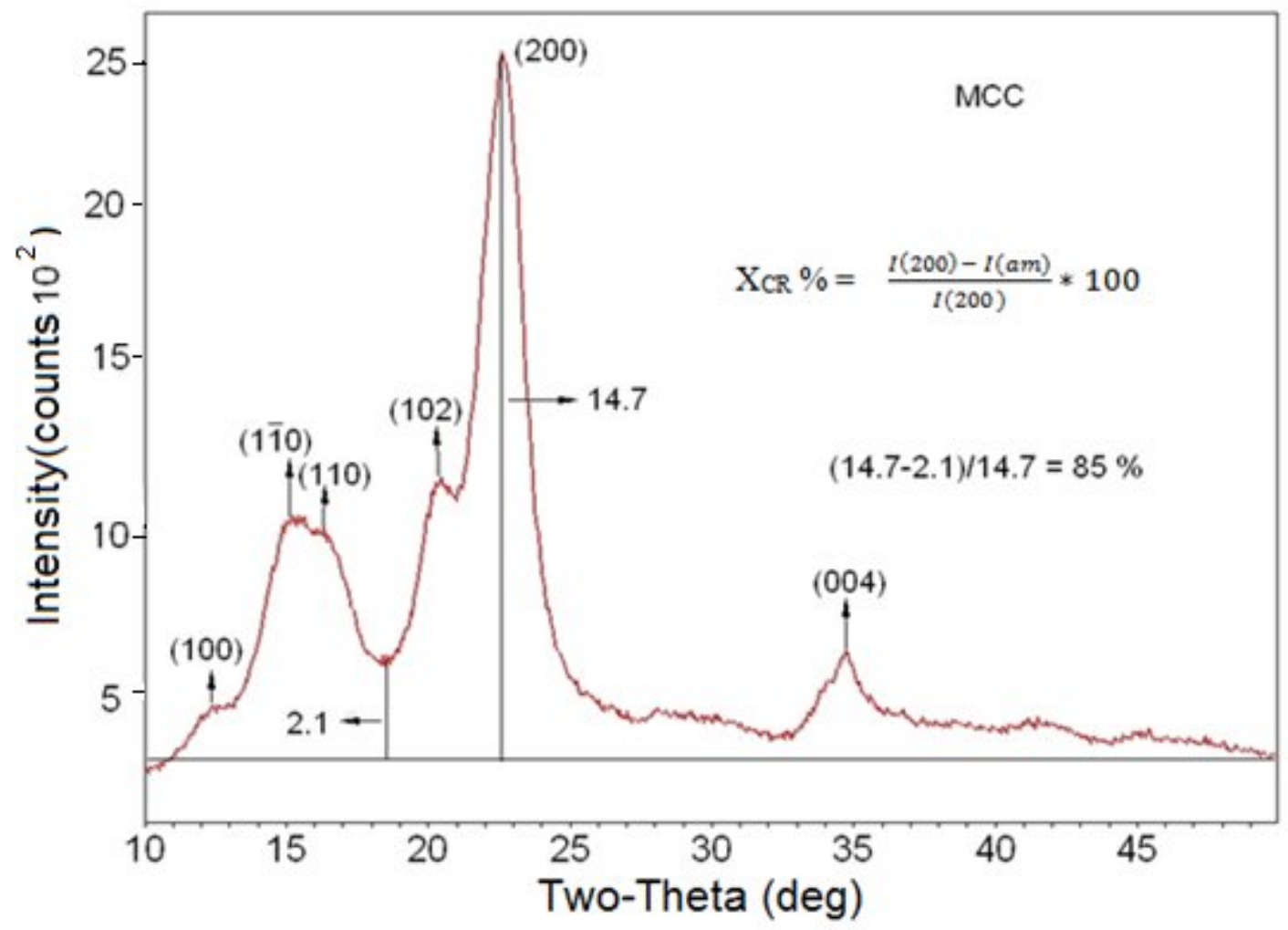

Fig.3.2: Calculation of Crystallinity

It is generally accepted that $\mathrm{X}_{\mathrm{CR}}$ measured by the Segal method is overestimated by about $10 \%$ because of the underestimation of $\mathrm{I}_{\mathrm{am}}(\mathrm{Park}$ et al, 2010). For the ball-milled sample, this uncertainty is even more enhanced because the position of the minimum to estimate $I_{a m}$ is shifting with increased $t_{\mathrm{BM}}$. Nevertheless, there is no uncertainty in the observation that increased $t_{B M}$ produces more amorphous cellulose. Since the presence of cellulose in the samples ballmilled for 60 min and 120 min cannot be proven with the XRD results alone, FTIR spectroscopy of these samples was also carried out which shows that the basic cellulosic structure in the 60 min and 120 min ball-milled samples is still present. These results are presented in the next section. Thus the major result for ball-milling up to $120 \mathrm{~min}$ is that an amorphous phase of cellulose is formed on ball-milling. Whether ball-milling for longer times can breakdown the cellulose structure still remains to be determined. 


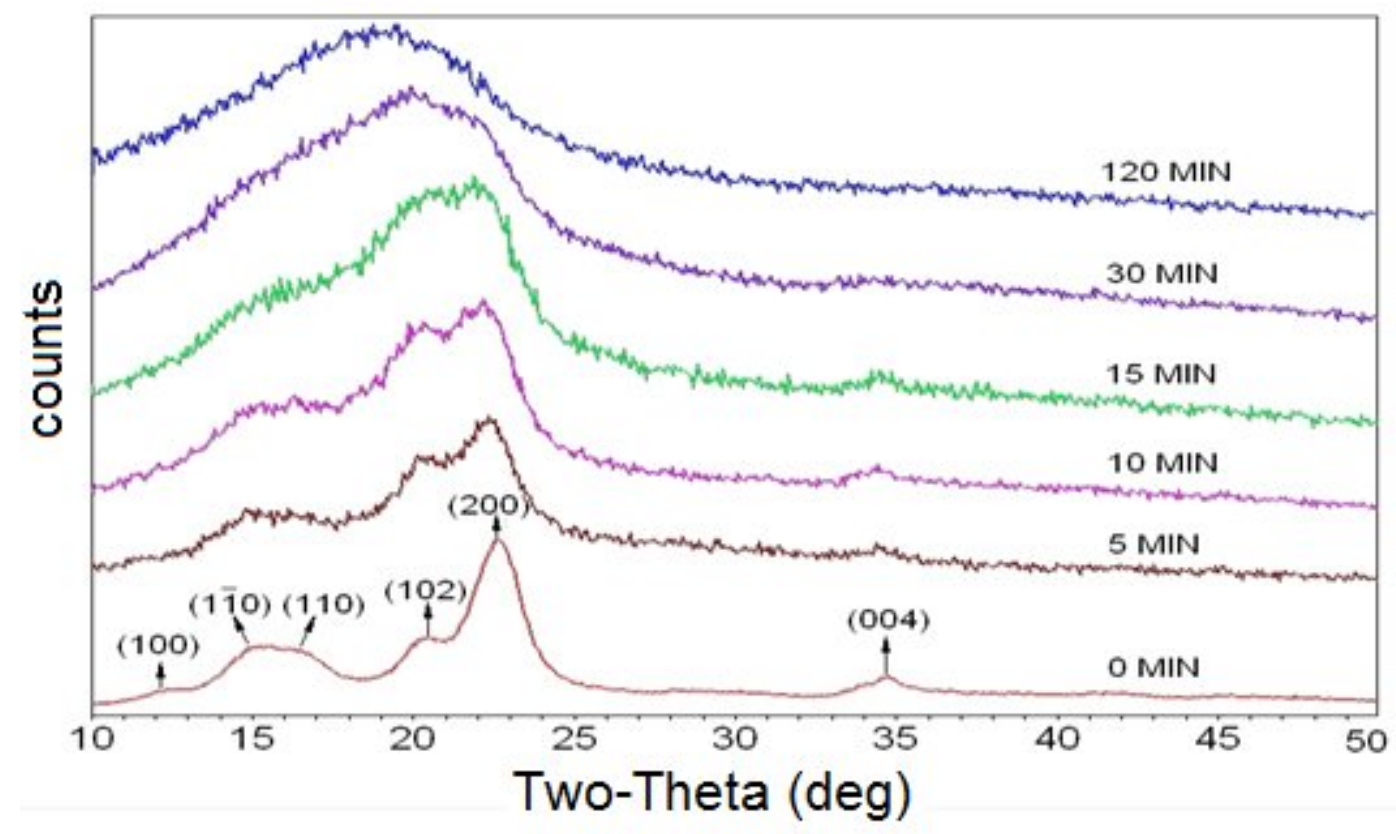

Fig.3.1: XRD patterns of the microcrystalline cellulose samples ball-milled for the different times listed on the figure. The Miller indices, (hkl), listed on the Bragg lines for the un-milled sample corresponds to the monoclinic structure of cellulose. The plots for different times are shifted vertically to accommodate all the curves.

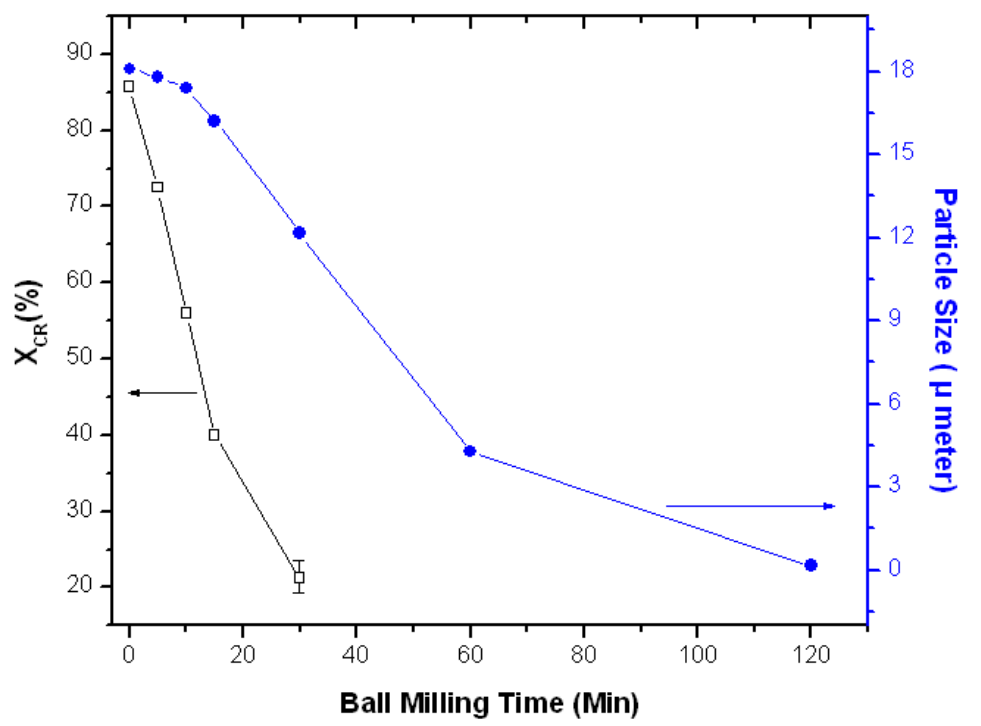

Fig. 3.3: Change in the Segal crystallinity parameter $X_{C R}(\%)$ and particle size with ball milling time. The lines connecting the data points are for visual guide. 
Table.3.1 Crystallinity of the ball-milled samples

\begin{tabular}{|l|l|c|}
\hline Ball Milled Time & Weight prepared in lab(grams) & $\mathrm{X}_{\mathrm{CR}} \%$ \\
\hline 0 & - & 85.70 \\
\hline 5 & 1.90 & 78.30 \\
\hline 10 & 1.40 & 68.70 \\
\hline 15 & 0.70 & 59.30 \\
\hline 30 & 0.70 & 7.0 \\
\hline 60 & 1.10 & - \\
\hline 120 & & - \\
\hline
\end{tabular}

The magnitudes of the lattice parameters a,b,c and the angle $\gamma$ of the monoclinic unit cell of cellulose can be determined from the experimental d-spacings of the (hkl) lines of the monoclinic structure utilizing the equation. (for example see Seehra et al2012)

$$
\frac{\sin \gamma}{d(h k l)}=\left\{\frac{h^{2}}{a^{2}}+\frac{k^{2}}{b^{2}}+\frac{l^{2} \sin ^{2} \gamma}{c^{2}}-\frac{2 h k \cos \gamma}{a b}\right\}^{1 / 2}
$$

For the MCC, the use of equation (2) yields $\mathrm{a}=7.87 \mathrm{~A}^{\circ}, \mathrm{b}=8.21 \mathrm{~A}^{\circ}, \mathrm{c}=10.38 \mathrm{~A}^{\circ}$ and $\gamma=94.0^{\circ}$, in good agreement with the recent determination of crystal structure of cellulose by Nishiyama et al (2002) using XRD and neutron scattering, reporting $\mathrm{a}=7.784 \mathrm{~A}^{\circ}, \mathrm{b}=8.210 \mathrm{~A}^{\mathrm{o}}, \mathrm{c}=10.380 \mathrm{~A}^{\circ}$ and $\gamma=96.5^{\circ}$. The resolution of the $(1,-1,0)$ and the $(1,1,0)$ doublet is essential for determining the magnitudes of $\mathrm{a}, \mathrm{b}$ and $\gamma$. 
Table 3.1 displays the crystallinity calculated for the MCC and the ball milled samples using the Segal method. It also lists the weight of the ball milled sample prepared in the lab.

\subsection{FTIR spectroscopy:}

A Mattson Infinity Gold FTIR spectrometer was used to obtain the IR spectra of MCC and ball-milled samples using the standard $\mathrm{KBr}$ method. In order to understand and discuss the FTIR spectra, the repeat unit of the polymer structure of cellulose is displayed in Fig.1.1. Cellulose, $\left(\mathrm{C}_{6} \mathrm{H}_{10} \mathrm{O}_{5}\right)_{\mathrm{n}}$, is a polymer made up of a chain of several thousand units of D-glucose, with the bonding between the different glucose-based units of the cellulose polymer occurring through the oxygen atom with the additional loss of $\mathrm{H}$ atoms of the $\mathrm{OH}$ group(Fig 1.1). Subsequently, the breakage of the C-O-C bond between the different sub-units of cellulose needs to occur to produce sugars.

The IR spectra of the untreated cellulose and the ball-milled samples are shown in Fig.3.4. It is apparent that there are significant changes in the IR spectra with increase in $t_{\mathrm{BM}}$ as shown in Fig3.4. Following the studies by Schwanninger et al (2004) on the IR spectra of wood and cellulose, these changes are discussed in terms of the changes in the structure of cellulose. In general, many of the sharp bands observed in the parent un-milled sample in the finger-print region of 500 to $1500 \mathrm{~cm}^{-1}$ become weaker with increased $t_{\mathrm{BM}}$.

First, the broad band in the 3000 to $3600 \mathrm{~cm}^{-1}$ and the relatively sharp band at $1648 \mathrm{~cm}^{-1}$, which are not significantly altered upon ball-milling, are known to be due to absorbed water. The sharp side-band at $3750 \mathrm{~cm}^{-1}$ appearing in the ball-milled samples is assigned to the vibration of the free $\mathrm{OH}$ group, as e.g. observed in the $\beta-\mathrm{Ni}(\mathrm{OH})_{2}$ structure (Rall et al, 2010). Normally, the $\mathrm{OH}$ groups in the linear cellulose structure are hydrogen-bonded to the other $\mathrm{OH}$ group in the adjoining cellulosic chains. Appearance of the free $\mathrm{OH}$ band on ball milling shows that ball-

milling breaks at least some of these inter-chain bonds thus reducing crystalline order. The composite band near $2900 \mathrm{~cm}^{-1}$ assigned to $-\mathrm{CH}_{2}$ (position 6 in Fig.1.1) and -CH- $\mathrm{O}$ (position 1 through 5 in Fig.1.1) groups of the cellulose structure(Chung et al, 2004) is largely unaffected by ball-milling. 


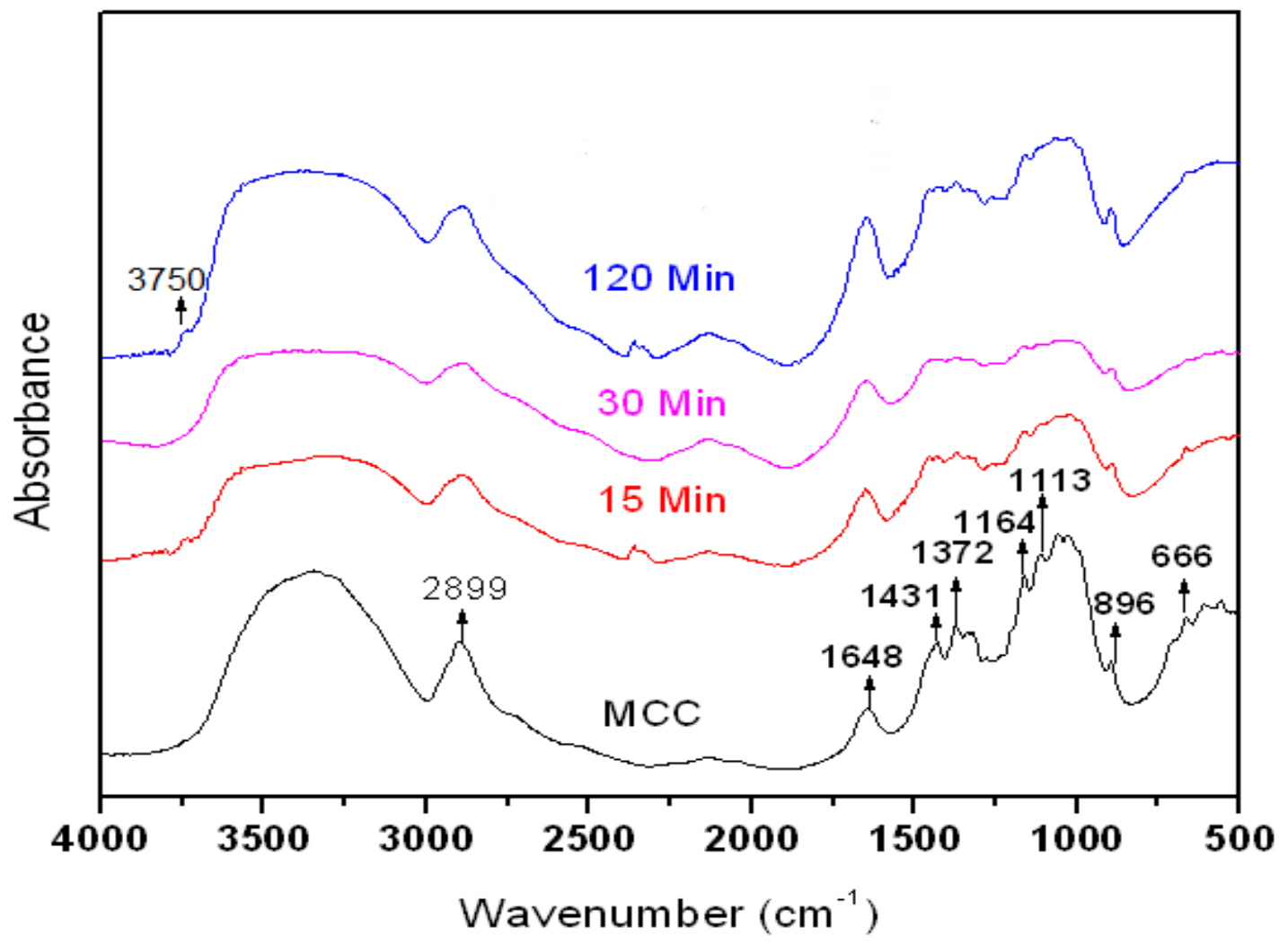

Fig.3.4: IR spectra of MCC samples ball-milled for different times are compared for the 500 to $4000 \mathrm{~cm}^{-1}$ range.

In the finger-print region below $2000 \mathrm{~cm}^{-1}$ shown in Fig. 3.4, the sharpness of peaks at $1372 \mathrm{~cm}^{-1}, 1164 \mathrm{~cm}^{-1}, 896 \mathrm{~cm}^{-1}$, and $666 \mathrm{~cm}^{-1}$ is unaffected by ball milling up to 120 minutes although some of the other bands are weakened by ball-milling. The band at $1372 \mathrm{~cm}^{-1}$ is assigned to the $-\mathrm{CH}-$ and $-\mathrm{CH}_{2}$ - modes of cellulose, the band at $1164 \mathrm{~cm}^{-1}$ to the $-\mathrm{C}-\mathrm{O}-\mathrm{C}-$ asymmetric stretch, the band at $896 \mathrm{~cm}^{-1}$ to the $\mathrm{C} 1$ group frequency, and the band at $666 \mathrm{~cm}^{-1}$ to the $-\mathrm{C}-\mathrm{OH}$ out of plane bending mode (see Table 3.2 based on the papers by Chung et al 2004, Schwanninger et al 2004, Seehra et al 2012). The integrity of these modes under ball-milling, in particular that of the $1164 \mathrm{~cm}^{-1}$ mode due to the bridging -C-O-C group, shows that the linear chain structure of cellulose remains largely intact under ball-milling although as noted above, data indicate that the inter-chain bonds are broken under ball- milling. This disruption of the inter-chain coupling would lead to significant crystalline disorder in agreement with the results obtained from XRD described above. 


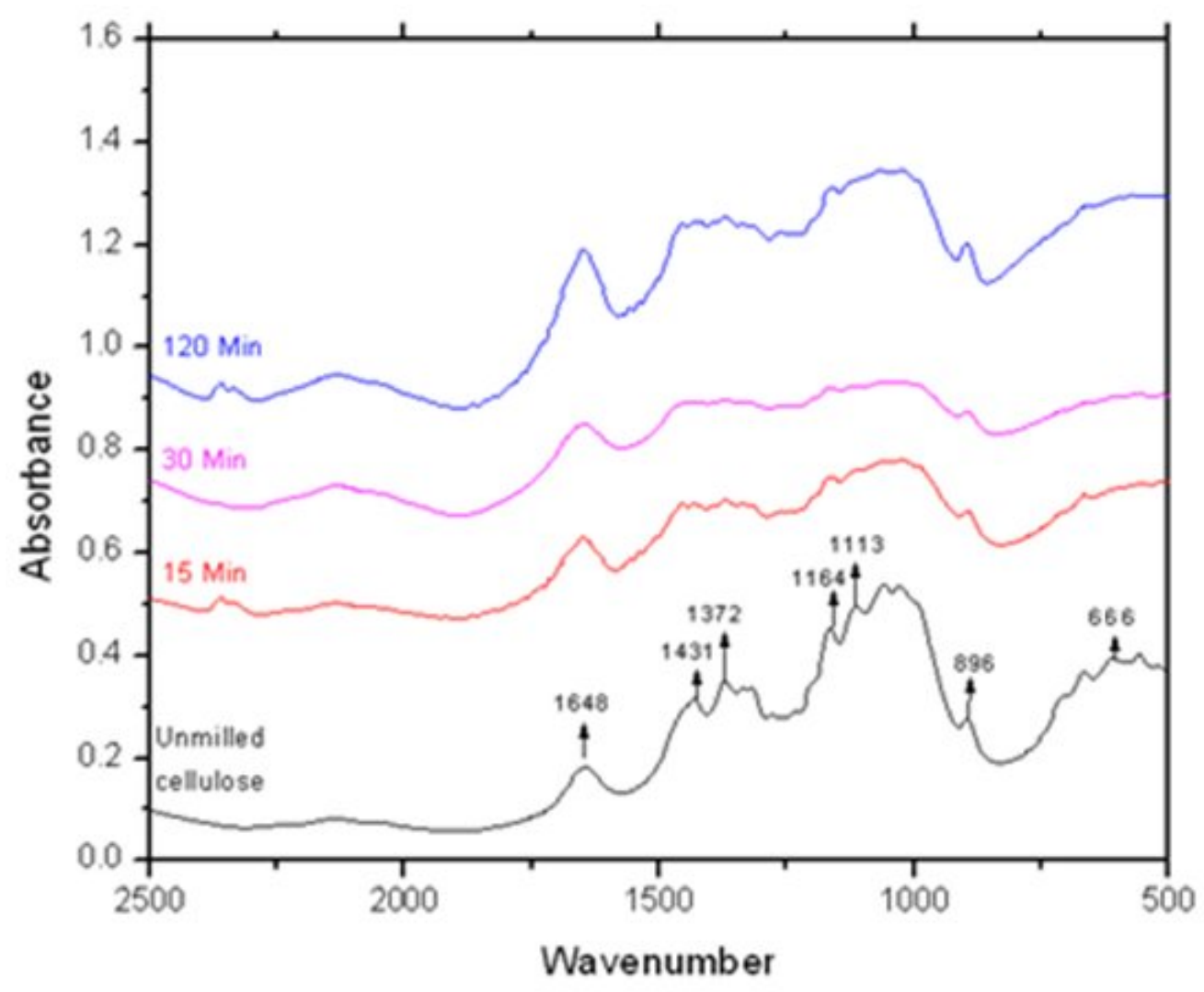

Fig. 3.5: IR spectra of MCC samples ball-milled for different times are compared for the 500 to $2500 \mathrm{~cm}^{-1}$ range.

Table 3.2 Assignments of the major IR bands (listed in $\mathrm{cm}^{-1}$ ) observed in the parent and post ball- milled samples.

\begin{tabular}{|l|l|l|l|l|}
\hline Parent MCC & $\begin{array}{l}\text { BM } \\
15 \text { Min }\end{array}$ & $\begin{array}{l}\text { BM } \\
30 \text { Min }\end{array}$ & $\begin{array}{l}\text { BM } \\
120 \text { Min }\end{array}$ & $\begin{array}{l}\text { Band } \\
\text { Origin }\end{array}$ \\
\hline 3330 & 3330 & 3330 & 3330 & $\begin{array}{l}\text { O-H stretch } \\
\text { O-H bending }\end{array}$ \\
\hline 1648 & 1648 & 1648 & 1648 & C-H stretching \\
\hline 2899 & 2899 & 2899 & 2899 & C-Hbending \\
\hline 1431 & 1455 & 1455 & 1455 & C-Hasymmetrical stretching \\
\hline 1372 & 1370 & 1370 & 1370 & C-O-Casymmetrical stretching \\
\hline 1164 & 1160 & 1160 & 1160 & C1group frequency \\
1113 & & 896 & 896 & -C-OH- out of plane bending \\
\hline 896 & 896 & 666 & 666 &
\end{tabular}



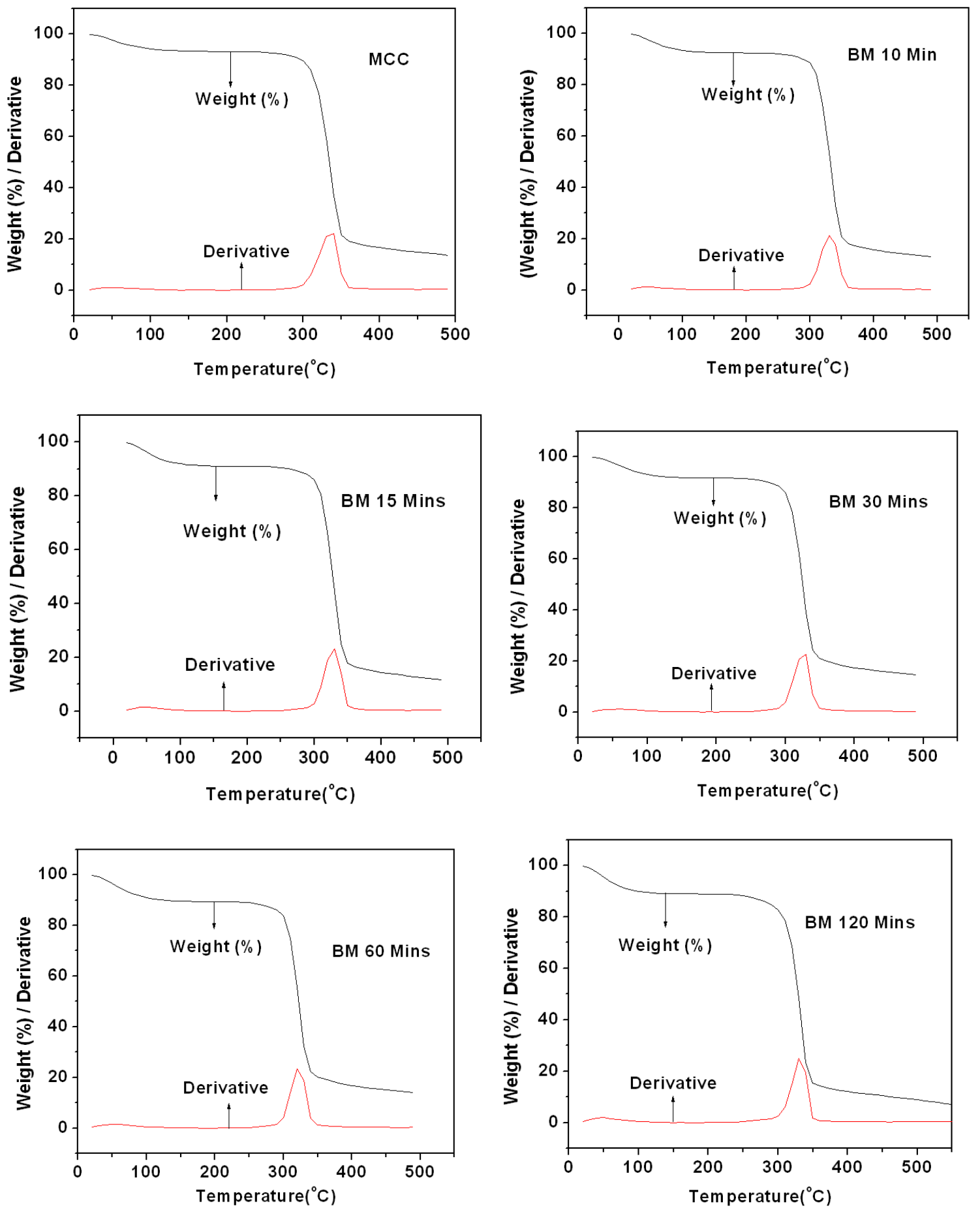

Fig. 3.6: TGA of ball-milled samples from $5 \mathrm{~min}$ to $120 \mathrm{~min}$

\subsection{Thermo-gravimetric analysis (TGA):}

Theresults from the TGA investigations on the cellulose samples ball-milled for different times are shown in Fig. 3.6.These measurements were done in nitrogen at a rate of $20^{\circ}$ per minute 
using TA Q 50 system. A derivative weight-loss curve can also be plotted on the same graph which is helpful in determining $T_{p}$, thetemperature at which the rate of weight-loss is maximum (see figure 3.7). The zenith point of the peak observed on the derivative curve is considered to be as the decomposition temperature of that material. This approach provides two important numerical information; the impurities in the sample (final mass) and decomposition temperature $\left(T_{P}\right)$. The decomposition temperature $\left(T_{P}\right)$ is defined as the difference of two temperatures $T_{i}$ and $T_{\mathrm{f} .} \mathrm{T}_{\mathrm{i}}$ is the temperature at which decomposition begins that is point at which the weight of the samples tends to decrease gradually and $\mathrm{T}_{\mathrm{f}}$ is the temperature at which decomposition is assumed to be completed where the weight of the sample nearly reaches a stable value. Thus the difference between $T_{i}$ and $T_{f}$ gives us the information on decomposition point of the material.

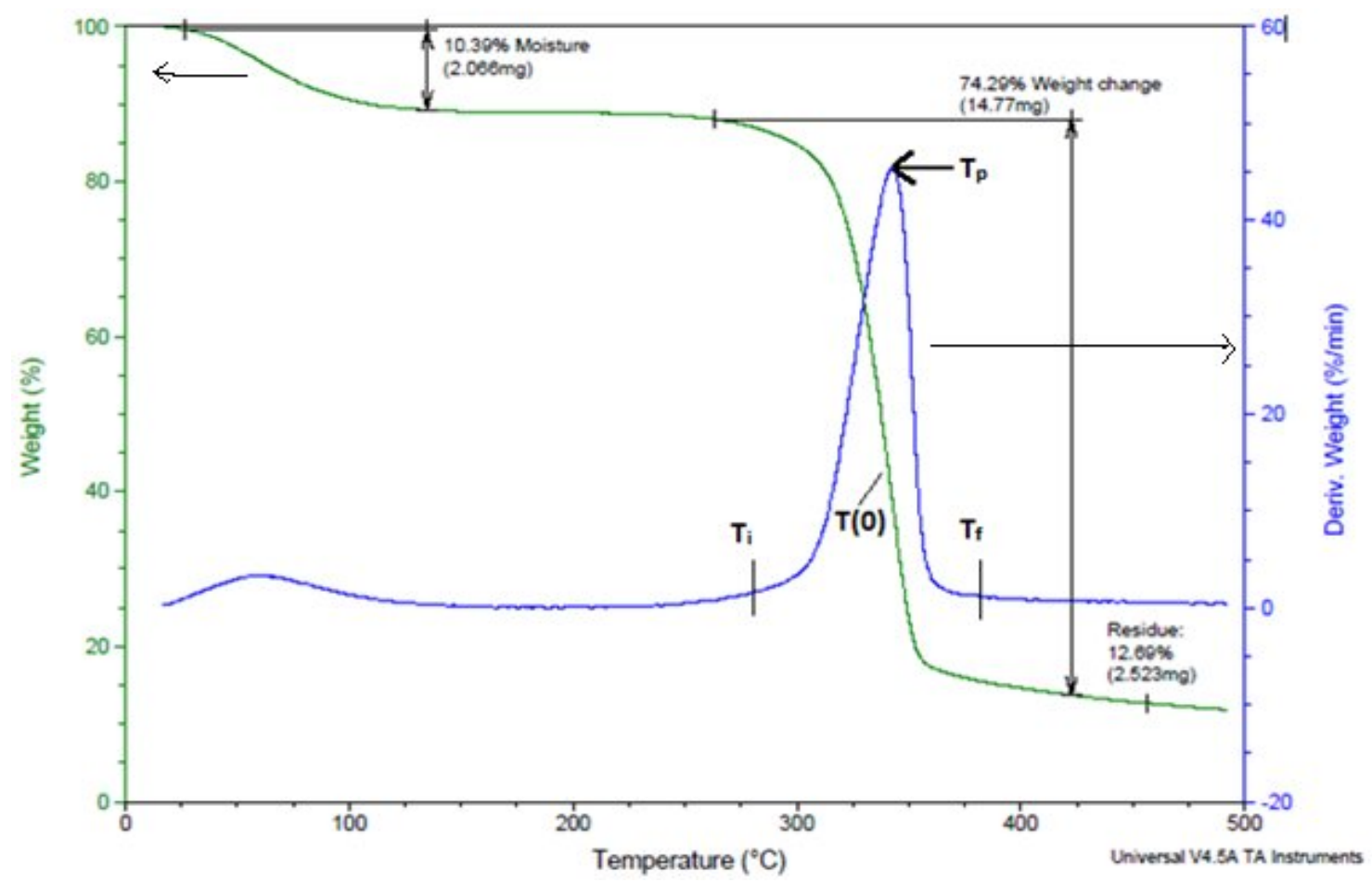

Fig 3.7 TGA of ball-milled cellulose for $120 \mathrm{~min}$

The major results from the TGA are combined in Fig.3.8. Generally, the decomposition of the cellulose occurs at about $350^{\circ} \mathrm{C}$. The weight loss of about $5 \%$ near $100^{\circ} \mathrm{C}$ was observed in all the samples and is likely from the loss of adsorbed moisture. Nearly $80 \%$ loss in the mass near $330^{\circ} \mathrm{C}$ in the MCC sample is assigned to the decomposition of cellulose. This $80 \%$ of the loss equals the degree of crystallinity determined for this sample using XRD. Hence, these 
observations support that the MCC sample contains about $80 \%$ crystalline cellulose, about $5 \%$ moisture and the remaining about 15\% amorphous components. The most interesting part of the results is systematic downward shift of the decomposition temperature of cellulose with increased $t_{\mathrm{BM}}$ except for the sample ball-milled for 120 minutes(Fig. 3.8). This suggests that the cellulose components in the higher ball-milled samples are easier to breakdown, perhaps due to the destruction of crystallinity of the sample.

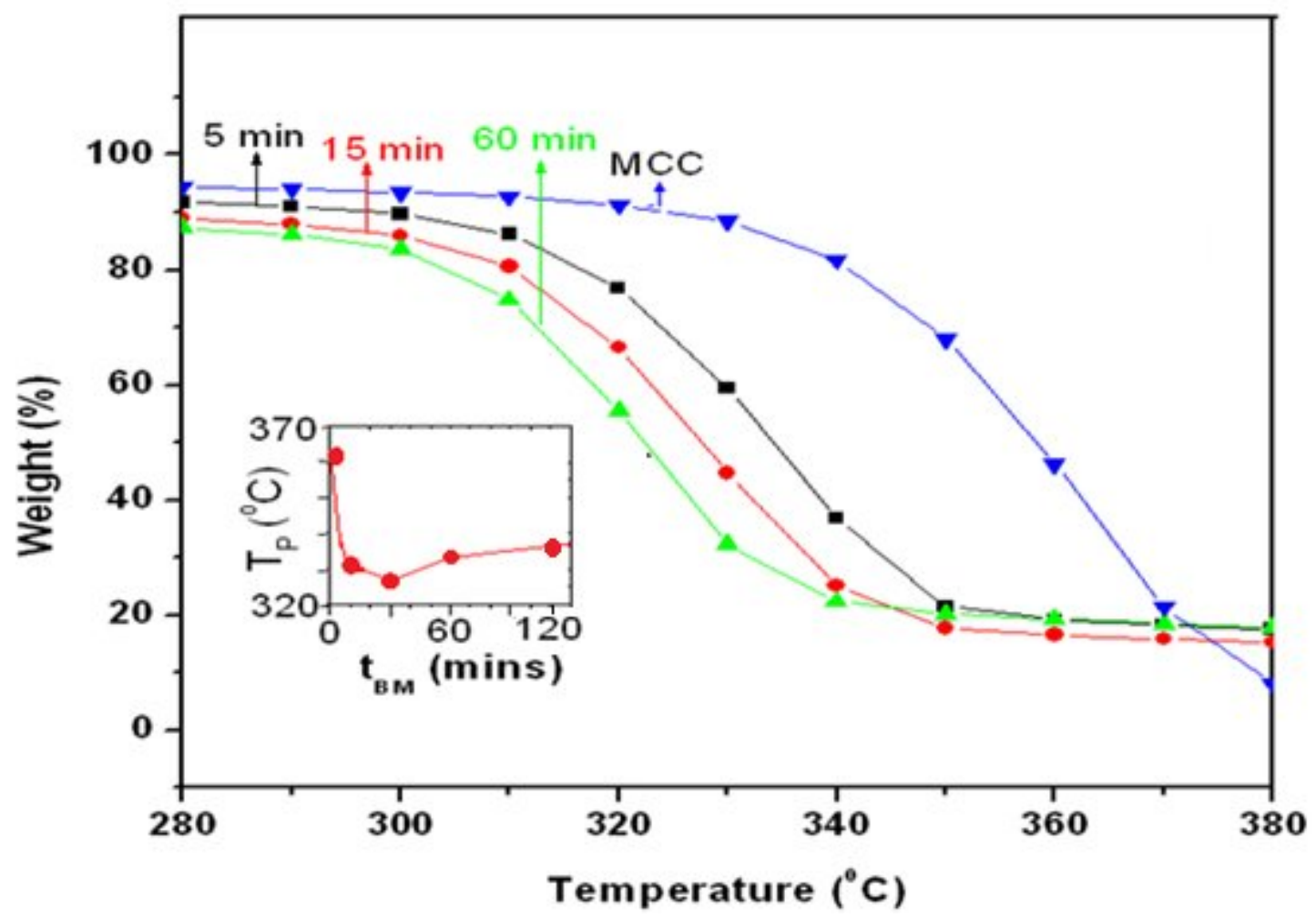

Fig. 3.8 TGA data of weight (W) change vs. temperature for several samples ball-milled for different times are shown. The inset shows the decomposition temperature $T_{P}$ determined by the peak in $\mathrm{dW} / \mathrm{dT}$ vs. $\mathrm{T}$ curves. Lines connecting the data points are visual guides.

The decomposition temperature $T_{\mathrm{p}}$ was determined by taking the derivative of the mass vs. temperature curve and the plot of $T_{p}$ vs. $t_{B M}$ is shown in the inset of Fig. 3.8. This decrease in $T_{p}$ on increased $t_{B M}$ is associated with the observed decrease in the crystalline order. The data on the 120 minute ball-milled sample does not fit this pattern in that $T_{p}$ for this sample is actually slightly higher than that for the 60 minute ball-milled sample (Fig. 3.8). This difference in the 
120 min ball-milled sampleis likely due to the change in the morphology of this sample as observed by SEM investigations described next.

\subsection{Scanning electron microscopy (SEM):}

The SEM micrographs of the cellulose samples ball- milled for different times are shown in Fig.3.9. The particle size of the parent sample of MCC as observed by SEM is about $12 \times 6$ $\mu \mathrm{m}^{2}$. With increased $t_{\mathrm{BM}}$, the average particle size is observed to decrease. (Table 3.2) For the 120 minute ball-milled sample, the ball-milling process produced spherical nanoparticles of amorphous cellulose of about $250 \mathrm{~nm}$ size. To our knowledge, this is the first observation of spherical nanoparticles of cellulose being produced by the ball-milling technique. These observations are distinctly different from a recent paper from our laboratory (Seehra et al 2012) where spherical particles by the hydrothermal treatment of cellulose also produced nanoparticles but with a chemical structure different from that of cellulose as evidenced by FTIR spectroscopy. As noted above, the material obtained after 120 minute ball-milling still has the cellulose structure although crystallinity of the sample is practically lost.

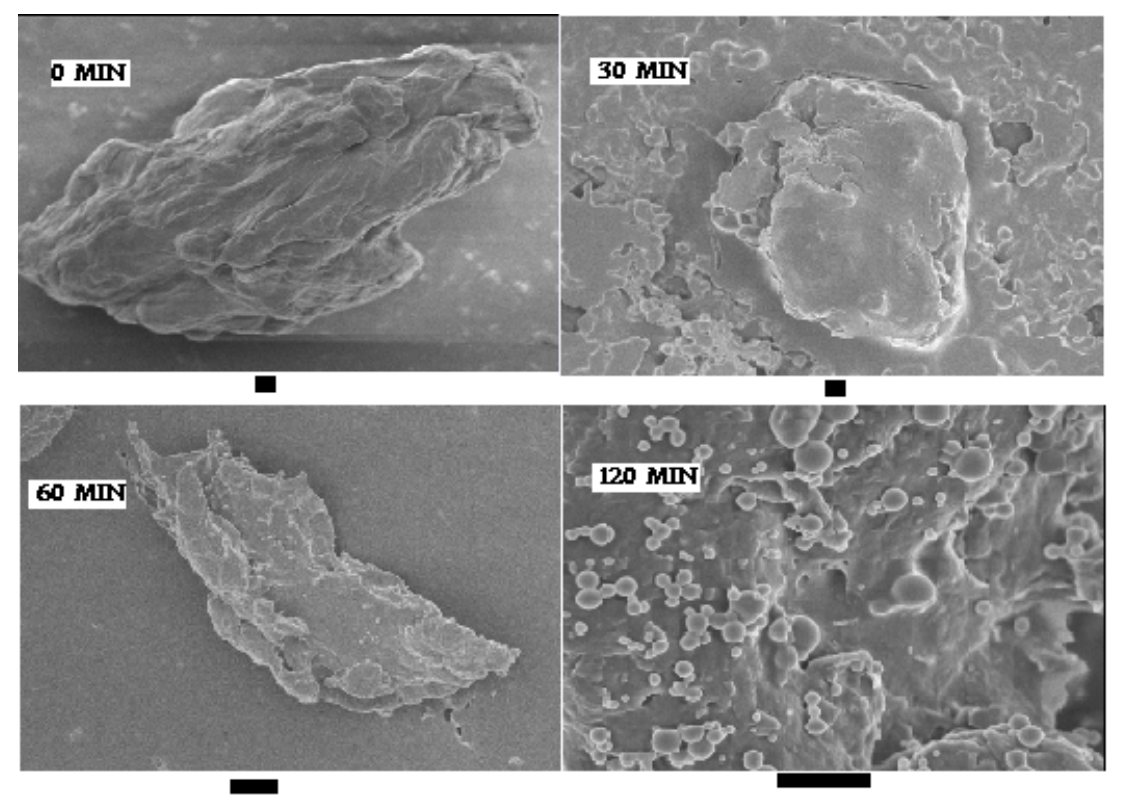

Figure 3.9: SEM micrographs for MCC samples ball-milled for different times. The lengths of the black scale bars are $1 \mu \mathrm{m}$. 
The Table 3.3 displays the particle size of the ball milled samples and the MCC measured using the Image J software with respect to the SEM images obtained. It is evident that as the ball milling time increases the particle size is decreasing at a substantial rate, the lowest particle size of about $0.15 \mu \mathrm{m}=150 \mathrm{~nm}$ is observed for the $120 \mathrm{~min}$ ball milled sample.

Table 3.3Ball-milling time vs.particle size

\begin{tabular}{|l|l|}
\hline Ball-milling time (min) & Average particle size $(\boldsymbol{\mu m})$ \\
\hline 0 & 18 \\
\hline 15 & 16 \\
\hline 30 & 12 \\
\hline 60 & 4 \\
\hline 120 & 0.15 \\
\hline
\end{tabular}

To determine the particle size distribution of the spherical particles for the $120 \mathrm{~min}$ ballmilled sample, all the circular particles were taken into consideration. The particle size distribution is plotted in Fig.3.10for the particles in the size range are between 0 to $300 \mathrm{~nm}$. The frequency indicates the number of particles present in the specified range. It is clear that most of the particles are about $150 \mathrm{~nm}$ in diameter. 


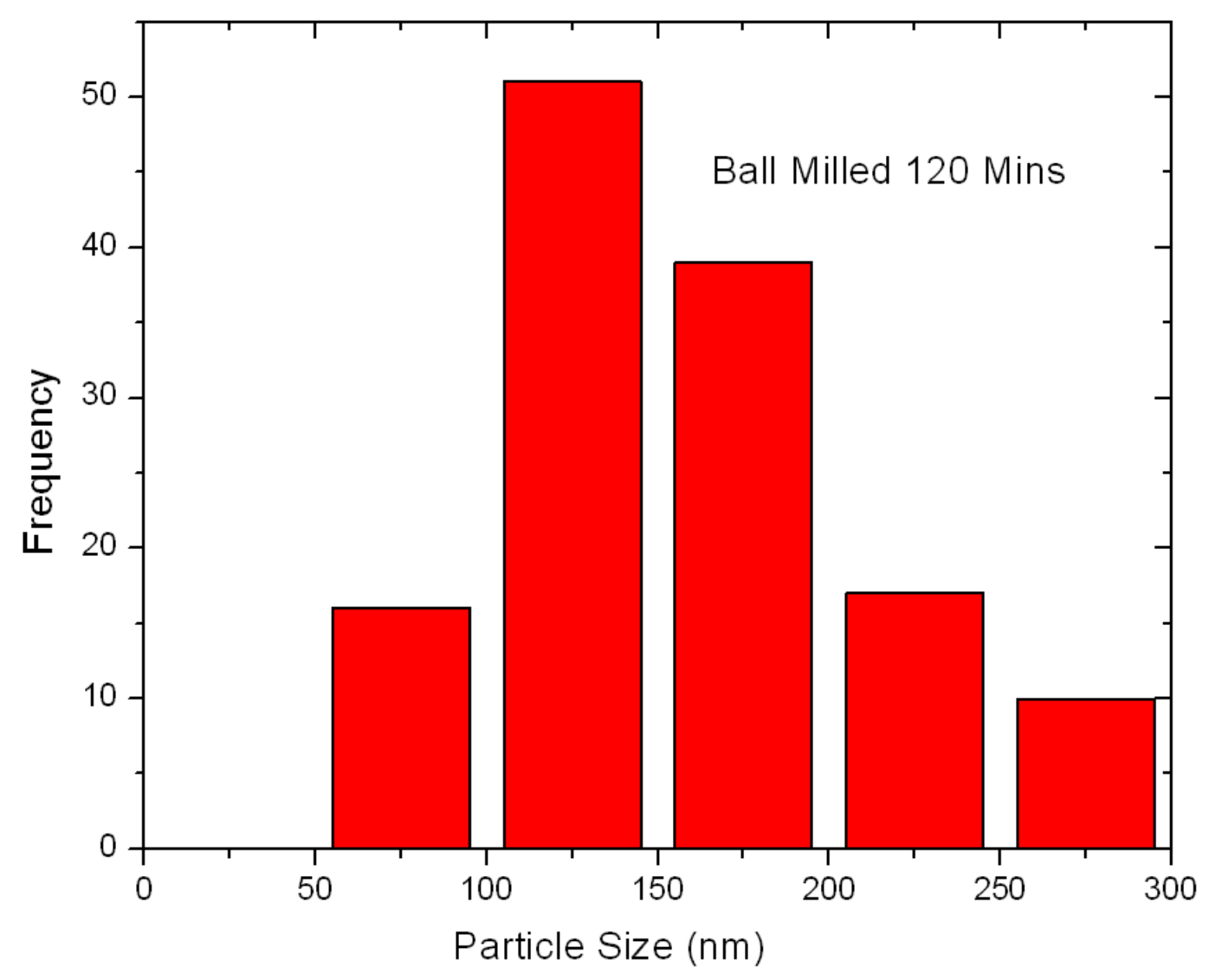

Fig. 3.10Particle size distribution of the 120 min ball-milled sample.

\subsection{Surface area:}

Measurements of the BET surface area of the particles after ball milling were carried out using the Micromeritics' AutoChem system. The results in Fig.3.11 show that the surface area and the total pore volume of the particles increase with increase in $t_{\mathrm{BM}}$, more than doubling for particles ball-milled for 30 minutes. For higher $t_{\mathrm{BM}}$, these quantities slowly decrease with increased $t_{\mathrm{BM}}$. These results are consistent with the change in $\mathrm{X}_{\mathrm{CR}}$ in Fig.3.2 and $\mathrm{T}_{\mathrm{P}}$ in Fig. 3.7 showing that the largest rate of change occurs for $\mathrm{t}_{\mathrm{BM}}<30$ minutes. 


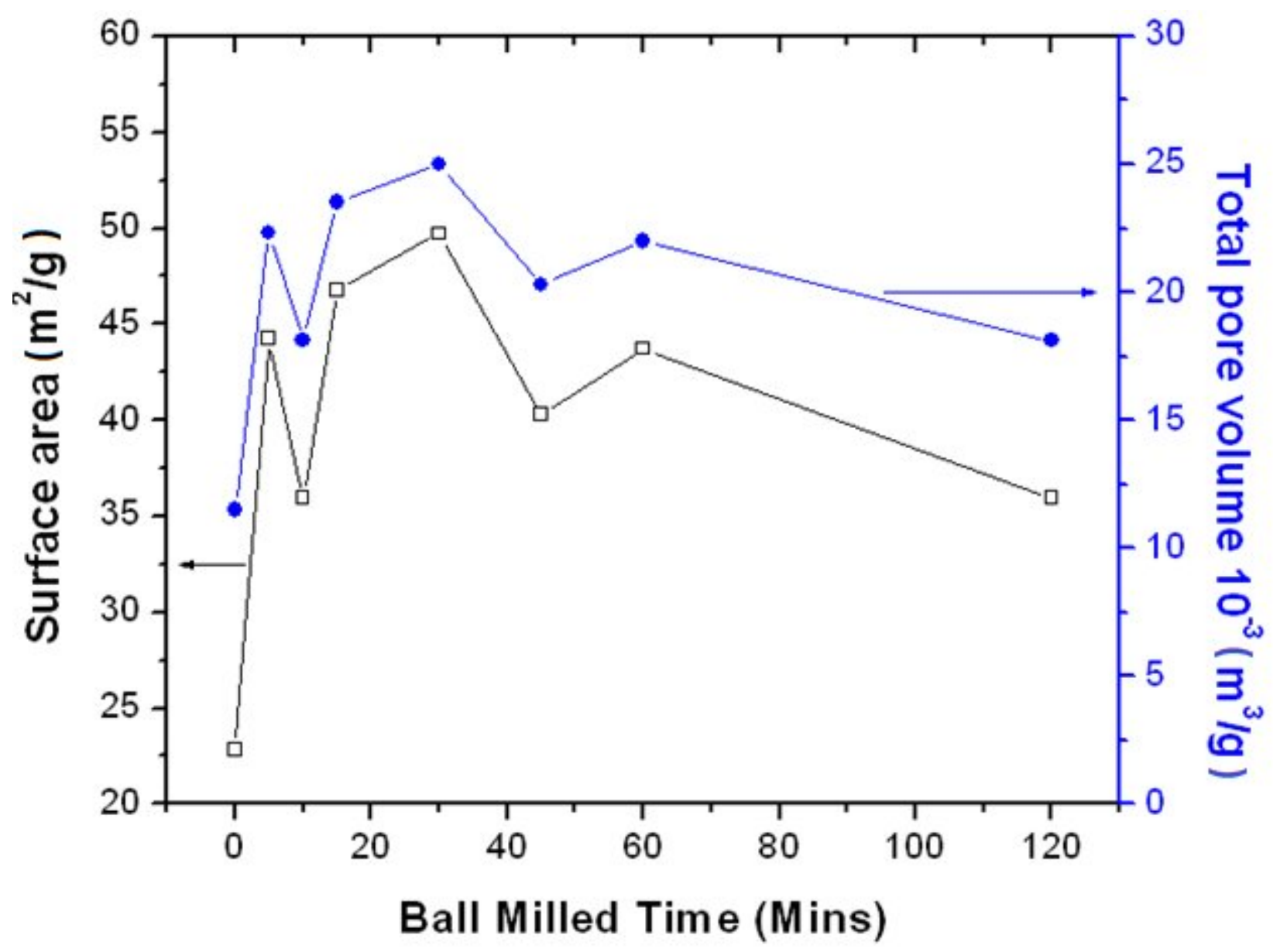

Fig. 3.11 BET surface area and total pore volume of the MC samples ball-milled for different times in minutes. The lines connecting the data points are visual guides. 


\section{EXPERIMENTAL RESULTS OF HTP CELLULOSE}

\section{1 Introduction:}

Microcrystalline cellulose (MCC) was subjected to hydrothermal treatment (HTT) for different temperature $(\mathrm{T})$, pressure $(\mathrm{P})$ and time $(\tau)$ conditions. In Table 4.1, the conditions of $\mathrm{T}$, $\mathrm{P}$ and $\tau$ for the various experiments in air and helium are summarized along with the percentage yields for nine cases. Note that the yield in Table 4.1 for converted samples is always less than $30 \%$.

Table 4.1 Magnitudes of the T, P and $\tau$ parameters for the different samples along with $\%$ recovery and $\%$ crystallinity (where applicable) are listed.

\begin{tabular}{|c|c|c|c|c|c|c|}
\hline $\begin{array}{l}\text { Gas in the } \\
\text { autoclave }\end{array}$ & SAMPLE & RESULT & CONDITIONS $(\mathrm{T}, \mathrm{P}, \tau)$ & $\begin{array}{l}\text { Final } \\
\text { Weight } \\
\text { (gms) }\end{array}$ & $\begin{array}{l}\text { \% } \\
\text { Recovery }\end{array}$ & $\begin{array}{l}\text { \% } \\
\text { crystallini } \\
\text { ty }\end{array}$ \\
\hline Air & $\mathrm{A}$ & Converted & 250C,550PSI,60MIN & 2.83 & 28.3 & - \\
\hline Air & $\mathrm{B}$ & $\begin{array}{l}\text { Not } \\
\text { converted }\end{array}$ & 220C,250PSI,60MIN & 3.01 & 30.1 & 90 \\
\hline Air & $\mathrm{C}$ & Converted & 250C,660PSI,60MIN & 3.61 & 36.1 & - \\
\hline Air & $\mathrm{D}$ & $\begin{array}{l}\text { Not } \\
\text { converted }\end{array}$ & 200C,220PSI,100MIN & 3.03 & 30.3 & 91 \\
\hline Helium & $\mathrm{E}$ & Converted & 250C,500PSI,60MIN & 2.73 & 27.3 & - \\
\hline Helium & $\mathrm{F}$ & $\begin{array}{l}\text { Partly } \\
\text { converted }\end{array}$ & 225C,377PSI,20MIN & 4.79 & 47.9 & 89 \\
\hline Helium & $\mathrm{G}$ & Converted & 230C,400PSI,35MIN & 2.42 & 24.2 & - \\
\hline Helium & $\mathrm{H}$ & $\begin{array}{l}\text { Not } \\
\text { converted }\end{array}$ & 220C,400PSI,15MINS & 4.78 & 47.8 & 93 \\
\hline Helium & I & $\begin{array}{l}\text { Partly } \\
\text { converted }\end{array}$ & 235C,435PSI,25MINS & 2.38 & 23.8 & 82 \\
\hline
\end{tabular}




\subsection{X-Ray Diffraction:}

The XRD patterns of the selected hydrothermally processed samples are shown in Fig. 4.1.It can be identified from the broad peaks that samples $A, G$ and $E$ are completely converted and the crystallinity is lost whereas F and I are partly converted. From a close examination of the $(\mathrm{P}, \mathrm{T}, \tau)$ conditions for various samples it is evident that temperature alone is not the only factor for conversion of MCC to a non-crystalline phase but pressure and time are also important. As noted earlier, the amorphous phase is defined by the loss of the individual Bragg peaks in the XRD pattern and the observation of a very broad pattern. It can be inferred from the figure that minimum magnitudes of $\mathrm{P} \simeq 400 \mathrm{psi}, \mathrm{T} \simeq 230^{\circ} \mathrm{C}$ and $\tau \simeq 30$ minutesin hydrothermal treatment are required to breakdown the crystallinity of the MCC.

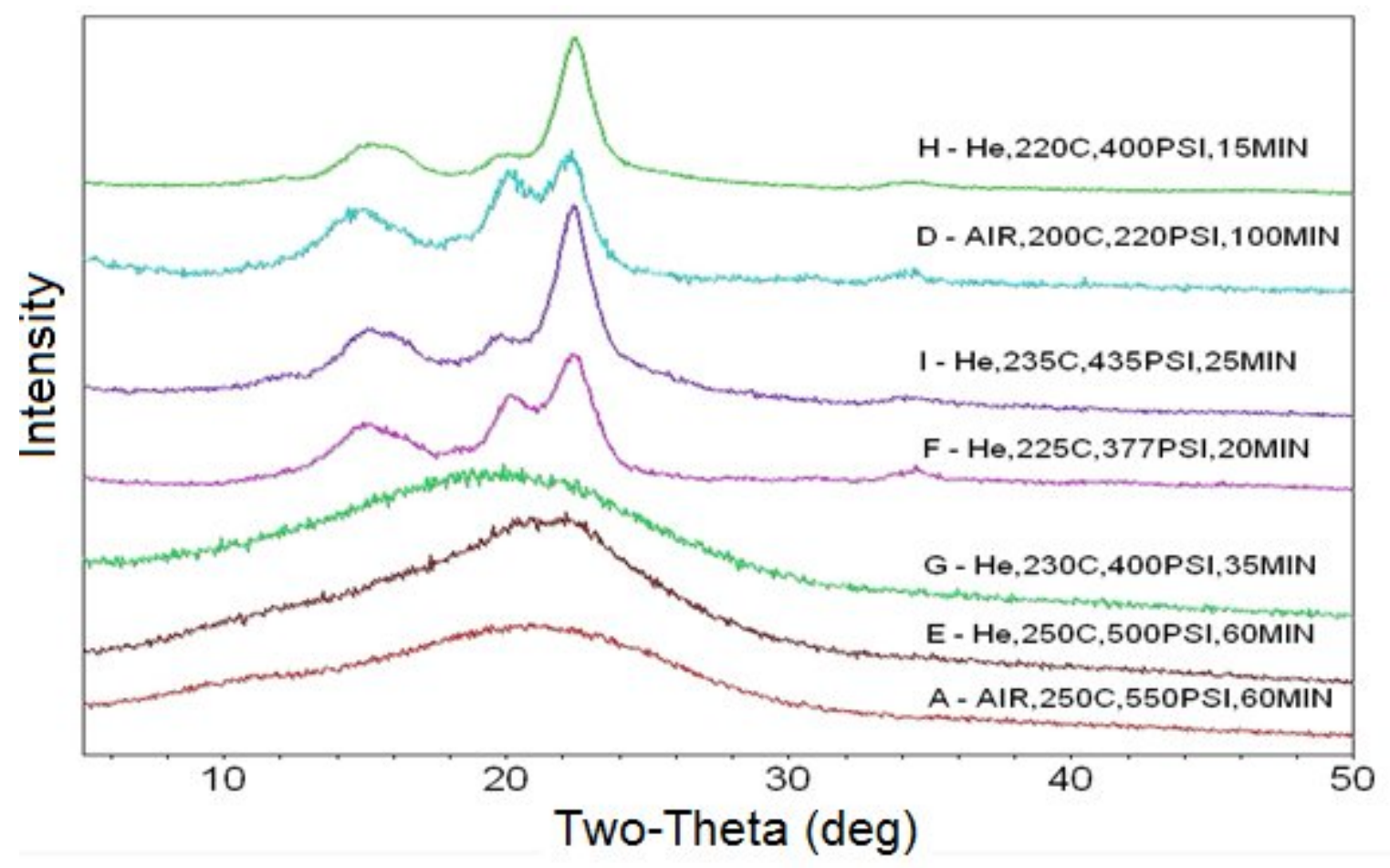

Figure 4.1: XRD patterns of the hydrothermally treated samples of MCC are shown. The conditions for the hydrothermal treatment are listed on each curve. 


\subsection{FTIR spectroscopy:}

Since the broad line observed in XRD (Fig. 4.1) cannot distinguish between amorphous cellulose and an entirely new chemical phase, FTIR spectroscopy of the HTT samples was carried out. The IR spectra of the various samples listed in Table I in the finger-print region of 500 to 2000 $\mathrm{cm}^{-1}$ are shown in Fig.4.2. All the spectra were acquired with an accumulation of 256 scans, resolution of $8 \mathrm{~cm}^{-1}$, in the range from 4000 to $400 \mathrm{~cm}^{-1}$.Changes in the relative intensities of the peaks in the finger print region 2000 to $400 \mathrm{~cm}^{-1}$ can be clearly seen in Fig.4.2. The peak around $1648 \mathrm{~cm}^{-1}$ observed in the untreated cellulose is due to the absorbed water molecules.In the HTT cellulose samples the band at $1648 \mathrm{~cm}^{-1}$ is split to form a three peak approximately at $1700 \mathrm{~cm}^{-1}$, $1600 \mathrm{~cm}^{-1}$ which are formed due to the carboxylate groups and peak at $1500 \mathrm{~cm}^{-1}$ which is due to $\mathrm{C}=\mathrm{O}$ stretching. The disappearance of the signature $896 \mathrm{~cm}^{-1}$ and $1164 \mathrm{~cm}^{-1}$ modes of cellulose in the converted samples differ from the results obtained under ball milling of MCC even for $\mathrm{t}_{\mathrm{BM}}=$ 120 minutes for which the presence of the $896 \mathrm{~cm}^{-1}$ band is clearly evident, Fig.4.3. This suggests that for the converted samples under HTT, the cellulose structure has completely broken down and a new chemical phase is formed. The different chemical nature of the converted sample is also evident from its thermal behavior under TGA as compared to that of the unconverted cellulose.

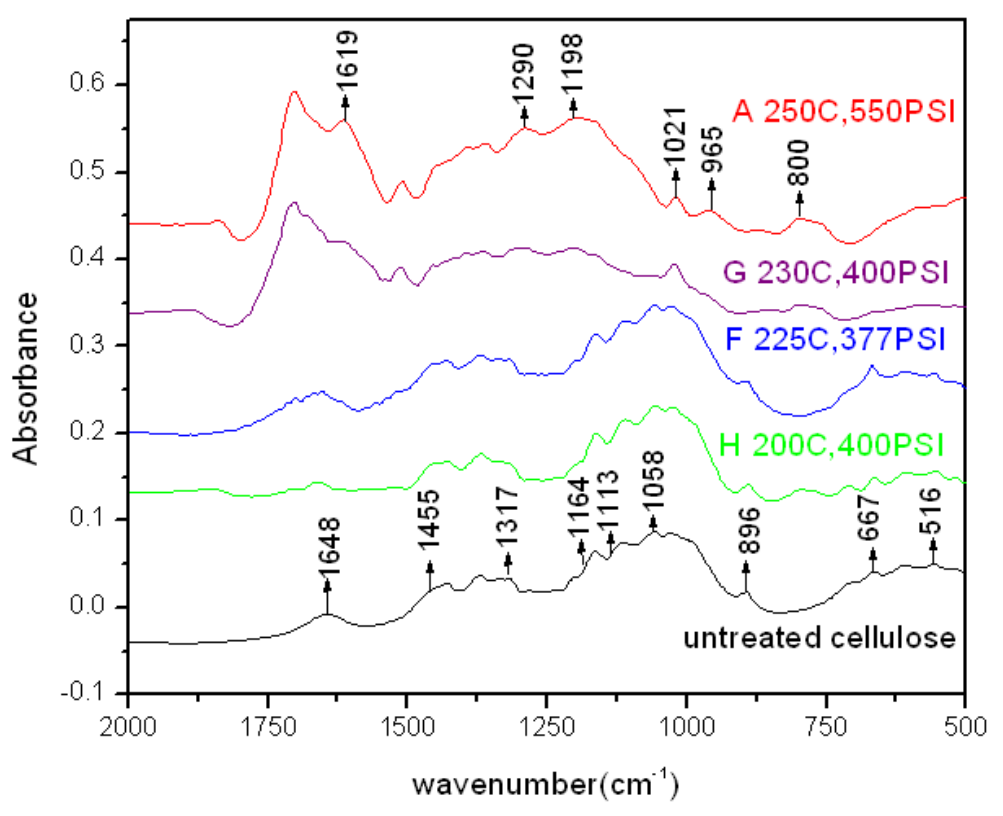

Fig. 4.2: FTIR Spectra for the $500 \mathrm{~cm}^{-1}$ to $2000 \mathrm{~cm}^{-1}$ range 
The cellulose peaks at 1455 and $1317 \mathrm{~cm}^{-1}$ are assigned to the $\mathrm{C}-\mathrm{H}$ stretching and the $1335 \mathrm{~cm}^{-1}$ is due to the $\mathrm{O}-\mathrm{H}$ in plane bending. The prominent peaks observed at $1164 \mathrm{~cm}^{-1}, 1113$ $\mathrm{cm}^{-1}$ are due to the asymmetric bridge C-O-C, $1058 \mathrm{~cm}^{-1}$ is due to the $\mathrm{C}-\mathrm{O}$ stretch. The weak peak at $896 \mathrm{~cm}^{-1}$ is due to the asymmetric out of phase ring stretch C-O-C. These peaks associated with the C-O-C bonds are either weakened or absent in the HTTproducts, which suggest the possibility of breakage of the polymer chain and formation of some glucose molecules. The weak peaks in the broad pattern at $700-400 \mathrm{~cm}^{-1}$ range are assigned to the $\mathrm{C}-\mathrm{C}$ stretching which corresponds to the tiny structures of sugars. This broad pattern is still present in HTT processed cellulose but the peaks are dissolved into the pattern.

The broad spectra centered at $3300 \mathrm{~cm}^{-1}$ corresponds to the $\mathrm{O}-\mathrm{H}$ stretching from the absorbed moisture. The broad peak observed at $3000-2800 \mathrm{~cm}^{-1}$ is due to the $\mathrm{C}-\mathrm{H}$ stretching from the $-\mathrm{CH}_{2}$ - and - $\mathrm{CH}$ - groups present in the cellulose structure. The different structures of samples $\mathrm{F}$ and $\mathrm{G}$ are evident from the differences in their IR spectra. The above assignments of various peaks, summarized in Table 4.2, are based on information from literature (Chung et al 2004, Schwanninger et al 2004, Seehra et al 2012).

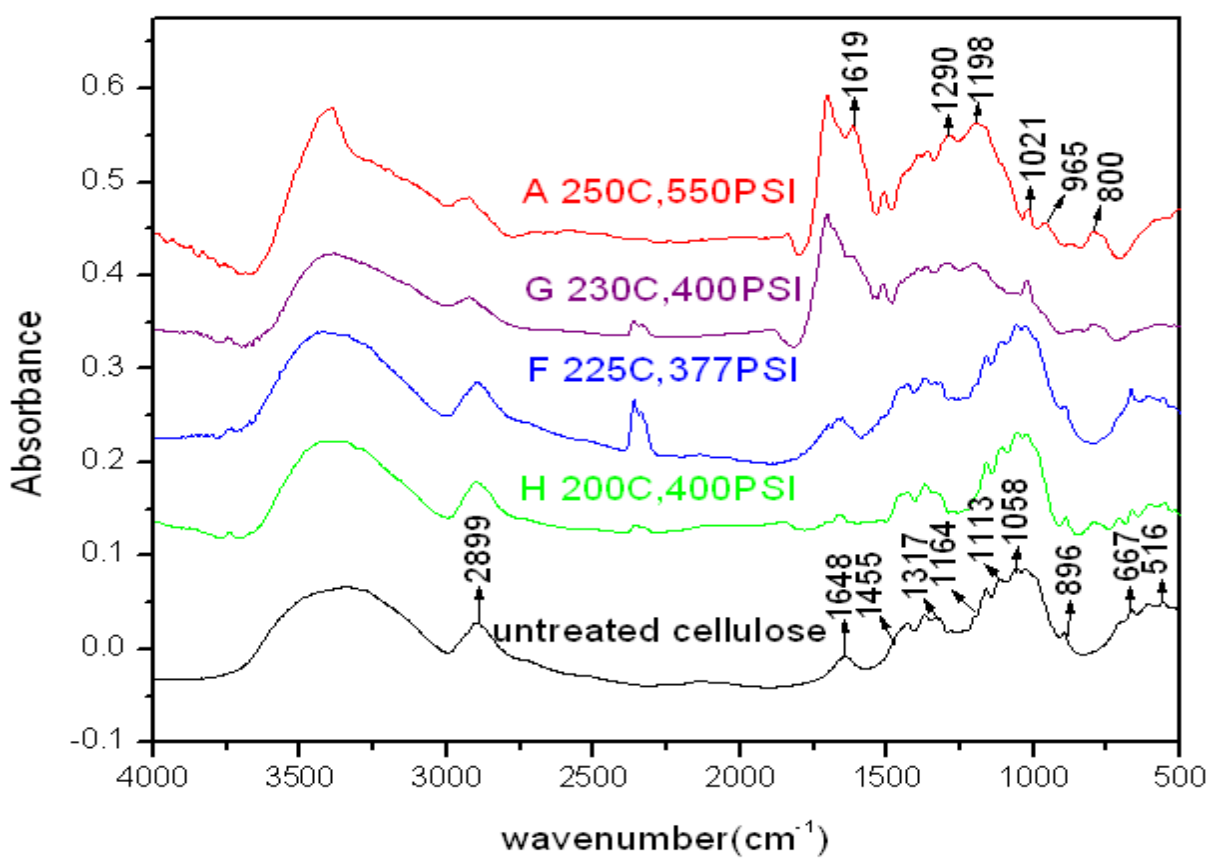

Fig. 4.3: FTIR spectra for the $500 \mathrm{~cm}^{-1}$ to $2000 \mathrm{~cm}^{-1}$ range 
Table 4.2. Assignments of the major IR bands (listed in $\mathrm{cm}^{-1}$ ) observed in the parent and postHTT samples.

\begin{tabular}{|c|c|c|c|c|c|}
\hline $\begin{array}{l}\text { Parent } \\
\text { MCC }\end{array}$ & Sample H & Sample F & Sample G & Sample A & $\begin{array}{l}\text { Band } \\
\text { Origin }\end{array}$ \\
\hline 3330 & 3330 & 3330 & 3330 & 3330 & O-H stretch \\
\hline 1648 & 1648 & 1648 & $\begin{array}{l}1700 \\
1500\end{array}$ & $\begin{array}{l}1700 \\
1619 \\
1500\end{array}$ & $\begin{array}{l}\text { Carboxylate groups } \\
\text { Carboxylate groups } \\
\mathrm{C}=\mathrm{O} \text { stretching }\end{array}$ \\
\hline 2899 & 2899 & 2899 & 2899 & 2899 & C-H stretching \\
\hline 1455 & 1455 & 1455 & 1455 & 1455 & C-H stretching \\
\hline 1317 & 1320 & 1320 & 1290 & 1290 & C-Hasymmetrical stretching \\
\hline $\begin{array}{l}1164 \\
1113\end{array}$ & $\begin{array}{l}1160 \\
1110\end{array}$ & $\begin{array}{l}1160 \\
1110\end{array}$ & 1110 & 1110 & $\begin{array}{l}\text { C-O-Casymmetrical } \\
\text { stretching }\end{array}$ \\
\hline 1058 & 1058 & 1058 & & & C-O strechhing \\
\hline 896 & 896 & 896 & & & C1group frequency \\
\hline 667 & 667 & 667 & & & $\begin{array}{l}\text {-C-OH- out of plane } \\
\text { bending }\end{array}$ \\
\hline
\end{tabular}

\subsection{Thermo-gravimetric analysis (TGA):}

Theresults from the TGA investigations on the HTP cellulose samples for different conditions are shown in Fig. 4.4. These measurements were done in nitrogen at the heating rate of $20^{\circ}$ per minute using TA Q 50 system. Generally, the decomposition of the cellulose occurs at about $350^{\circ} \mathrm{C}$. The weight loss of about $5 \%$ near $100{ }^{\circ} \mathrm{Cwas}$ observed in all the samples and is likely from the loss of adsorbed moisture. Nearly $85 \%$ loss in the mass near $360^{\circ} \mathrm{C}$ in the sample $\mathrm{F}$ and $\mathrm{H}$ is assigned to the decomposition of cellulose. This $85 \%$ of the loss equals the degree of crystallinity determined for this sample using XRD. Hence, these observations support that the MCC sample contains about $85 \%$ crystalline cellulose, about 5\% moisture and the remaining about $10 \%$ amorphous components. The most interesting part of the results is systematic downward shift of the decomposition temperature of cellulose with increased temperature, pressure and time conditions. This suggests that the cellulose components in the unconverted samples are easier to breakdown, perhaps due to the destruction of crystalline components. The 
converted sample A shows a different thermal behavior proving the formation of a different chemical phase. Results of the TGA and FTIR show that for higher P, T and $\tau$ the cellulose structure has completely broken-down and a new chemical phase is formed. This different chemical nature of the converted sample is evident from its thermal behavior under TGA as compared to that of unconverted sample.

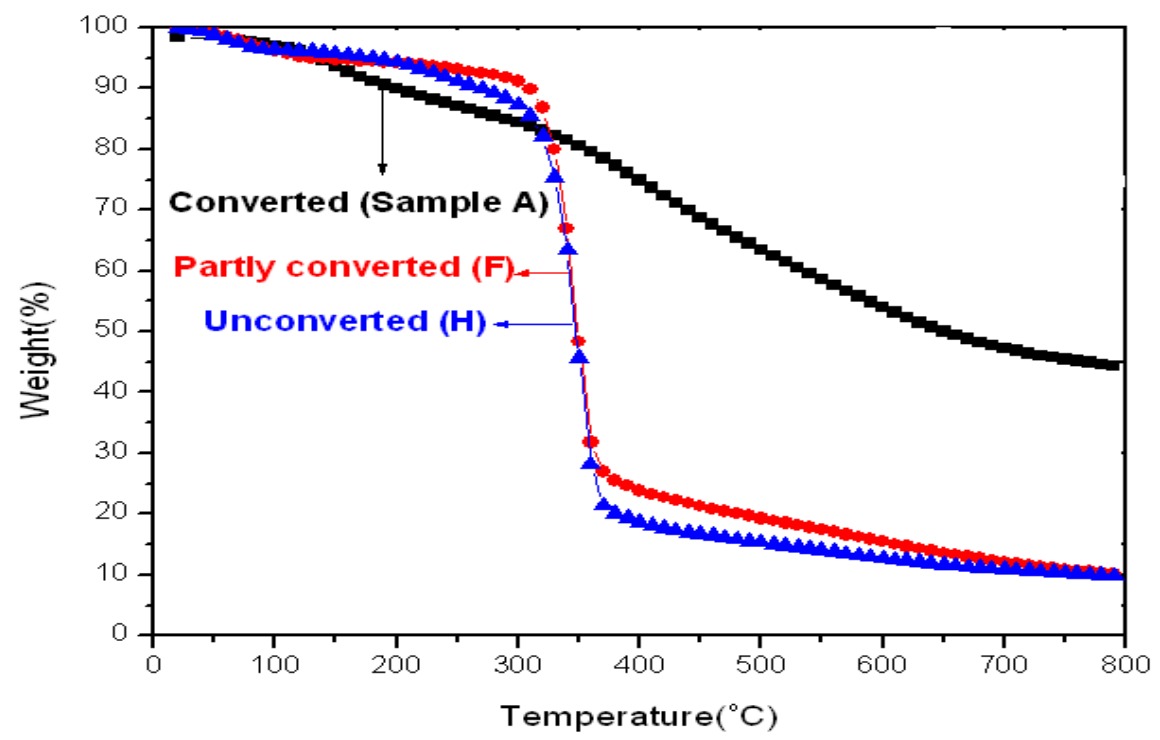

Fig. 4.4 TGA plot of the three hydrothermally processed MCC samples of Table 4.1.

\subsection{Scanning electron microscopy (SEM):}

The SEM micrographs of the HTTcellulose samples for different conditions are shown in Fig.4.5, Fig.4.6and Fig.4.7. The particle size of the parent sample of MCC as observed by SEM is about $12 \times 6 \mu \mathrm{m}^{2}$. With increased conditions of T, P and $\tau$, the average particle size is observed to decrease. For the converted sample A, the hydrothermal treatment produced spherical nanoparticles of about $150 \mathrm{~nm}$ size. From the SEM pictures it is clearly evident that the particle size of converted samples is considerably less than that of the partly converted and the unconverted samples. 


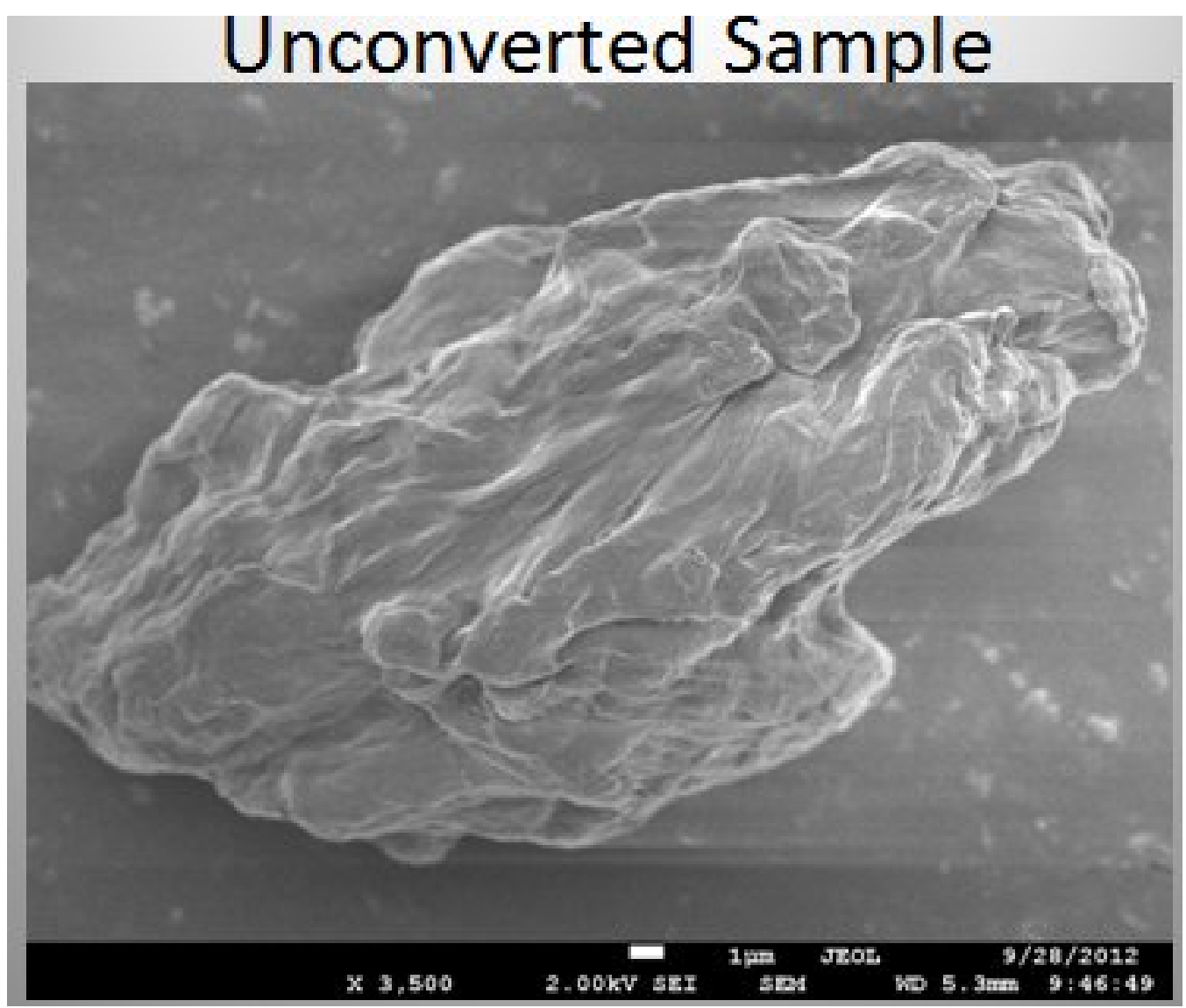

Fig. 4.5 SEM micrographs of the unconverted sample

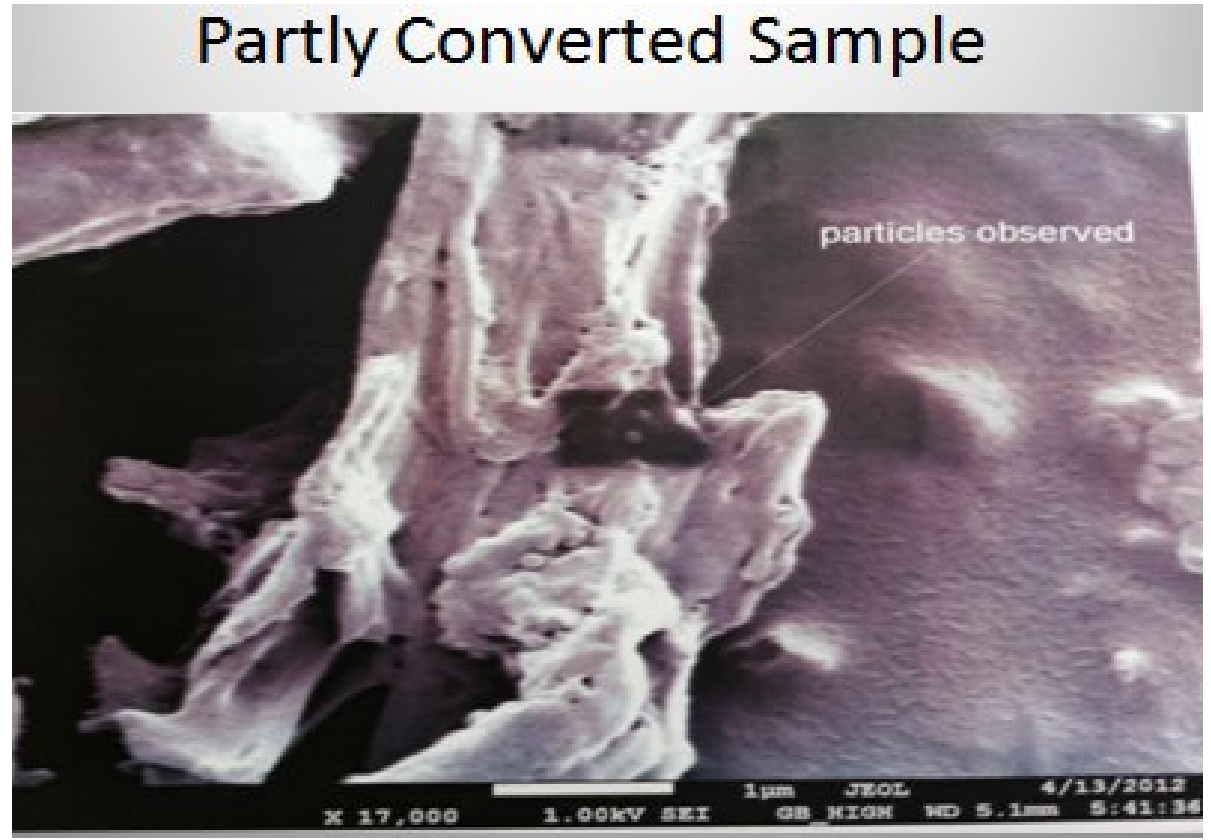

Fig.4.6 SEM micrographs of partially converted sample showing formation of spherical particles 


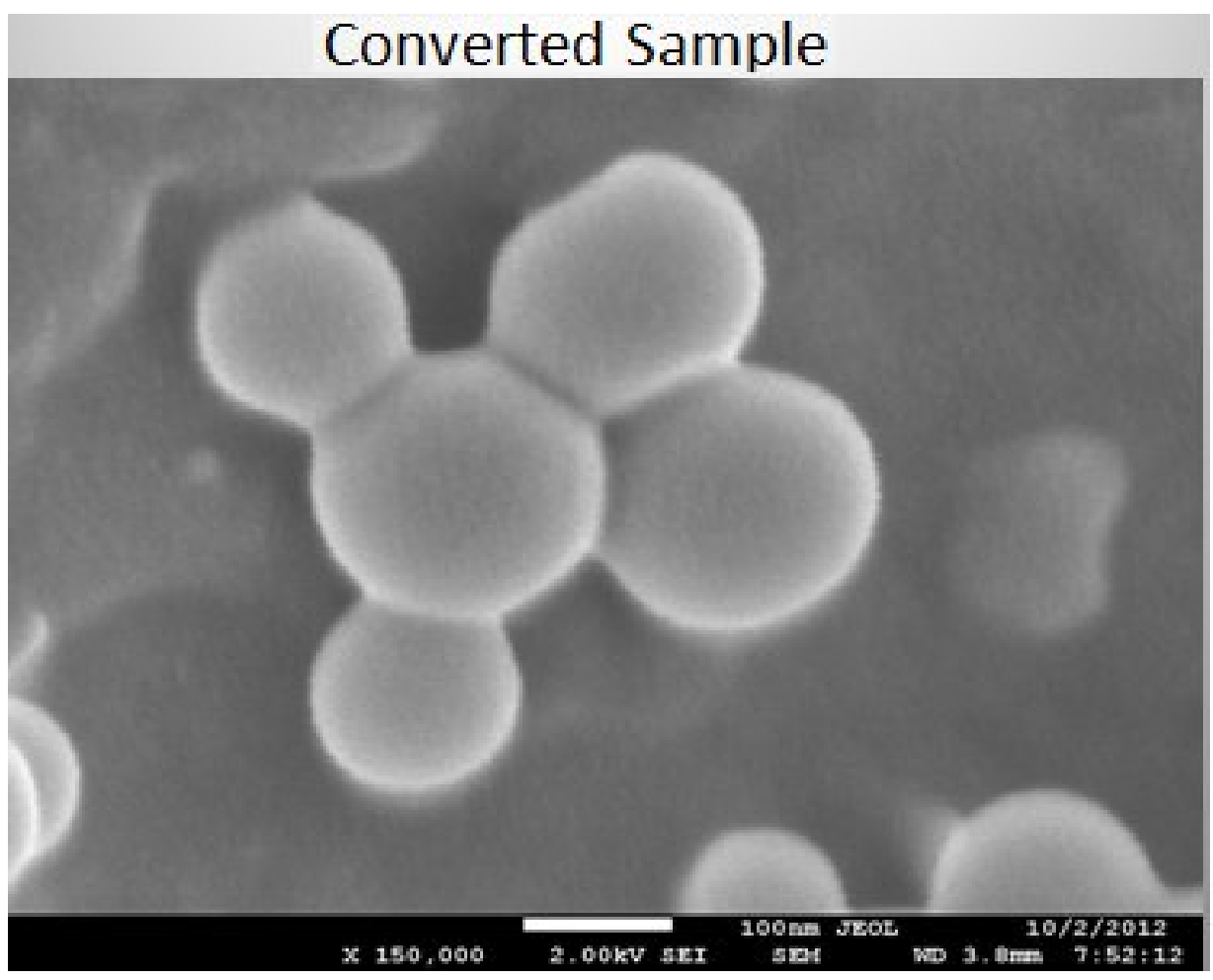

Fig. 4.7 SEM micrographs of converted sample showing nearly spherical particles

The particle sizes of the HTTconverted samples were determined using ImageJ software. The results in Fig. 4.8 illustrate the information on the number of particles present in a particular range. For instance, there are no particles with the particle size below $50 \mathrm{~nm}$ and there are 68 particles in the size range of $150 \mathrm{~nm}$ to $200 \mathrm{~nm}$.

A fit to log-normal distribution logarithmic curve is also plotted with the $\mathrm{D}_{0}$ and $\sigma$ values adjusted such that the logarithmic curve fits nicely on the bar graph. From the Table 4.2 it is evident that the frequency of the particles tends to increase from 50 to $200 \mathrm{~nm}$ and then decreases. 


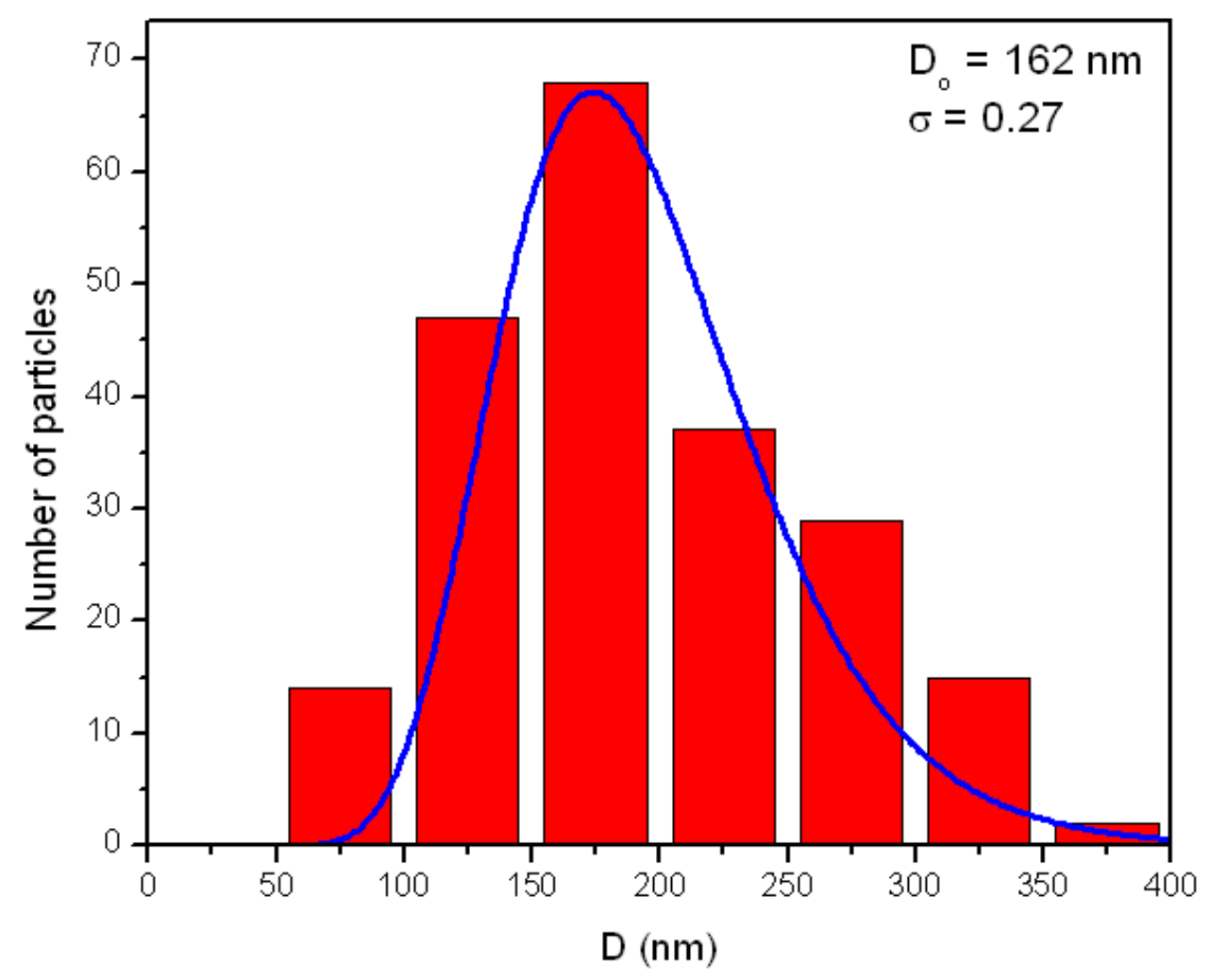

Fig. 4.8Size distribution of the spherical particles present in the converted sample. The solid curve is the $\log$ normal distribution function. $\mathrm{f}(\mathrm{x})=\frac{1}{\sqrt{2 \pi \sigma x}} \exp \left(-\frac{[\ln (x)-\mu]^{2}}{2 \sigma^{2}}\right), \mu=\ln (D)$ 
Table 4.3 Particle size of the converted HTP MCC sample

\begin{tabular}{|l|l|}
\hline Partticle Size(nm) & Frequency \\
\hline $0-25$ & 0 \\
\hline $25-50$ & 0 \\
\hline $50-75$ & 6 \\
\hline $75-100$ & 8 \\
\hline $100-125$ & 27 \\
\hline $125-150$ & 20 \\
\hline $150-175$ & 33 \\
\hline $175-200$ & 35 \\
\hline $200-225$ & 21 \\
\hline $225-250$ & 16 \\
\hline $250-275$ & 20 \\
\hline $275-300$ & 11 \\
\hline $300-325$ & 1 \\
\hline $325-350$ & \\
\hline $350-375$ & \\
\hline $375-400$ & \\
\hline $400-425$ & \\
\hline
\end{tabular}




\section{CONCLUSIONS}

Results and the discussion on the phase transformation of MCC under ball-milling and hydrothermal treatment have been presented. Under ball-milling, systematic decreases in crystallinity index $X_{C R}$, thermal decomposition temperature $T_{p}$ and particle size with increased ball-milling time $t_{\mathrm{BM}}$ is reported with the largest rates of change observed for $\mathrm{t}_{\mathrm{BM}}<30 \mathrm{~min}$. Results from FTIR show that although linear structure of polymer chains is maintained under ball-milling up to $120 \mathrm{~min}$, crystallinity is lost and there is evidence for the breakage of the interchain bonds. Thus under ball-milling, MCC transforms to an amorphous state. The formation of the spherical particles of amorphous cellulose under $120 \mathrm{~min}$ ball-milling is one of the interesting results of these investigations.

Results from the hydrothermal treatment(HTT) of MCC show complete breakdown of the cellulose structure for $\mathrm{P} \simeq 400 \mathrm{psi}, \mathrm{T} \simeq 230^{\circ} \mathrm{C}$ and $\tau \simeq 30$ minutes, a minimum in the $\mathrm{P}, \mathrm{T}, \tau$ conditions. For $\mathrm{P}<400$ psi and $\mathrm{T}<230^{\circ} \mathrm{C}$, there appears to be no significant change in the structure of MCC implying that the breakdown of the cellulosic structure involves a first order transition. In TGA under nitrogen flow where only temperature is changed, breakdown of the cellulose structure occurs near $330^{\circ} \mathrm{C}$. In the experiments reported by Deguchi et al (2006) using optical spectroscopy under a constant pressure of $25 \mathrm{MPa}$ (3627 psi), a transition from crystalline to amorphous form of cellulose was observed at $330^{\circ} \mathrm{C}$ followed by a breakdown of cellulose structure at $340^{\circ} \mathrm{C}$. These transition temperatures under $25 \mathrm{MPa}$ pressure nearly equal the transition we observe in TGA under normal pressure. On the other hand under HTT, cellulose structure breaks down at the much lower temperature of $230^{\circ} \mathrm{C}$ using $\mathrm{P}=400 \mathrm{psi}$ only. Thus breakdown of the cellulose structure under hydrothermal treatment requires milder $(\mathrm{P}, \mathrm{T})$ conditions. This is an important result of this work.

Some general characteristics of the solid products formed under HTT of cellulose have been identified. Further work is needed to identify the specific chemical products formed under HTT not only in the recovered solid product but also in the liquid which was not analyzed in this work. These tasks are left for future investigations. 


\section{References:}

1. Browing BL. "The chemistry of wood Huntington", (Krieger Publishing Co, 1965, NY).

2. Charles M. "Compositional Analysis by Thermogravimetry" (ASTM, 1988, PA)

3. Christopher H. "Basics of crystallography and diffraction", (Oxford Science Publications, 2001, NY).

4. Chung C, Lee M, Choe EK. "Characterization of cotton fabric scouring by FT-IR ATR spectroscopy” Carbohydrate Polymers 2004; 58: 417-420.

5. Cullity B.D. "Elements of X-ray diffraction", (Addison-Wesley, 1956, MA).

6. Deguchi S, Tsujii K and Horikoshi K, "Cooking cellulose in hot and compressed water", Chem. Commun. 2006; 31:3293-5.

7. Earnest C M, "The use and extended lifetimes of microfurnaces for thermogravimetry: Part I Construction, application, and cleaning" ThermochimicaActa 1990; 158: 157-166.

8. Habibi Y, Lucian A.L, Orlando J.R "Cellulose Nanocrystals: Chemistry, Self-Assembly, and Applications” Chem. Rev. 2010; 110: 3479-3500.

9. Kolpak F J, Weih M, Blackwell J. "Mercerization of cellulose: Determination of the structure of mercerized cotton", Polymer 1978; 19:123-131.

10. Moon R J, Ashlie M, John N, John S and Jeff Y, "Cellulose nanomaterials review: structure, properties and nanocomposites”, Chem. Soc. Rev., 2011; 40: 3941-3994.

11. Mansikkamaki P, Lahtinen M, Rissanen K "structural changes of cellulose crystallites induced by mercerization in different solvent systems determined by powder X-ray diffraction method", Cellulose 2005; 12(3):233-242.

12. Nishiyama $Y$, Langan P, Chanzy H. "Crystal structure and hydrogen-bonding system in cellulose $\mathrm{I}_{\beta}$ from synchrotron X-ray and neutron fiber diffraction", J. Am. ChemSoc 2002; 124:9074-82.

13. Pandey K.K, Theagarajan K.S, "Analysis of wood surfaces and ground wood by diffuse reflectance (DRIFT) and photoacoustic (PAS) Fourier transform infrared spectroscopic techniques", HolzRohWerkstoff, 1997; 55:383-390. 
14. Park S, Baker J, Himmel M, Parilla P and Johnson D. "Research Cellulose crystallinity index: measurement techniques and their impact on interpreting cellulase performance", Biotechnology for biofuels. 2010; 3:10.

15. Rall J D, Seehra M S, Choi E S, "Metamagnetism and nanosize effects in the magnetic properties of the quasi-two-dimensional system $\beta$ - Ni(OH) $)_{2}$, Phys. Rev. 2010; B82, 184403/1-9.

16. Schwanninger R, Pereira H, Hinterstoisser. B, "Effects of short-time vibratory ball milling on the shape of FT-IR spectra of wood and cellulose", Vib. Spectrosc. 2004; 36: 23-40.

17. Seehra.M.S, Akkineni L.P, Yalamanchi M, Singh V, PostonJ . "Structural characteristics of nanoparticles produced by hydrothermal pretreatment of cellulose and their applications for electrochemical hydrogen generation” Inter. J. Hydrogen Energy, 2012; 37: 9514-9523.

18. Segal L, Creely JJ, Martin AE, Conrad CM. "An empirical method for estimating the degree of crystallinity of native cellulose using the X-ray diffractometer." Textile Res. J 1959; 29:786-94.

19. Smith B.C. "Fundamentals of Fourier Transform Infrared spectroscopy", (Taylor and Francis Group, 2011, FL).

20. Wang. S, Liu Q, Luo Z, Wen L, Cen K. "Mechanism study on cellulose pyrolysis using thermogravimetric analysis coupled with infrared spectroscopy", Front. Energy Power Eng. China 2007; 1(4): 413-9. 
Approval of the Examining Committee

Muhammad A. Choudhry, Ph.D., Chair

Mohindar S. Seehra, Ph.D., Co-Chair

Yuxin Liu, Ph.D.

July 8, 2013 